\title{
Shelf Flows Forced by Deep-Ocean Anticyclonic Eddies at the Shelf Break
}

\author{
DEEPAK A. CHERIAN ${ }^{\mathrm{a}}$ AND K. H. BRINK \\ Woods Hole Oceanographic Institution, Woods Hole, Massachusetts
}

(Manuscript received 14 November 2017, in final form 14 March 2018)

\begin{abstract}
Isolated monopolar eddies in the ocean tend to move westward. Those shed by western boundary currents may then interact with the continental margin. This simple picture is complicated by the presence of other flow features, but satellite observations show that many western boundary continental shelves experience cross-shelfbreak exchange flows forced by mesoscale eddies translating near the shelf break. Here we extend our previous study of eddy interaction with a flat shelf to that with a sloping shelf. Using a set of primitive equation numerical simulations, we address the vertical structure of the onshore and offshore flows forced by the eddy, the origin of the exported shelf water, and the extent to which eddy water can penetrate onto the shelf. The simulations reveal an asymmetry in the vertical structure of cross-shelfbreak flows: the offshore flow is generally barotropic, whereas the onshore flow is always baroclinic. The exported shelf water is sourced from downstream of the eddy in the coastal-trapped wave direction and is supplied by a barotropic alongshore jet. This "supply jet" has a Rhines-like cross-shore length scale proportional to (eddy velocity scale/shelf topographic beta) ${ }^{1 / 2}$ measured from the shelf break. Eddy water is forced onto the shelf and is present up to a distance of one internal Rossby deformation radius, defined using shelf properties, from the shelf break. We rationalize these horizontal and vertical scales, connect them to existing observations, and extend our previous parameterization of eddy-forced offshore shelf-water flux to account for nonzero shelf slopes.
\end{abstract}

\section{Introduction}

Deep-water mesoscale anticyclonic eddies interact with continental shelf-slope topography in many parts of the world: for example, the Mid-Atlantic Bight (MAB) off the northeastern United States (Joyce et al. 1992), the Gulf of Alaska (Okkonen et al. 2003), the east Australian shelf (Tranter et al. 1986), and others. At the shelf break, these eddies export shelf water offshore (e.g., Fig. 1; Joyce et al. 1992) while also transporting eddy and slope waters on to the shelf (e.g., Lee and Brink 2010; Zhang and Gawarkiewicz 2015). Eddyforced fluxes are one of many time-dependent mechanisms that could accomplish the shelf-water export and deep-water import required to satisfy volume, heat, and salt budgets for the Mid-Atlantic Bight (Brink 1998; Lentz 2010). The relative importance of such eddyforced fluxes in satisfying these shelf budgets is still

\footnotetext{
${ }^{\text {a }}$ Current affiliation: College of Earth, Ocean, and Atmospheric Sciences, Oregon State University, Corvallis, Oregon.
}

Corresponding author: Deepak A. Cherian, dcherian@coas. oregonstate.edu unconstrained (Cherian and Brink 2016). In addition, there are biological implications to the export of shelf water-increased warm-core ring activity at the MidAtlantic Bight shelf break has been linked to decreased recruitment for some fish species (Myers and Drinkwater 1989).

Beyond fluxes, eddy interactions can substantially change water-mass and flow properties on the outer shelf, at least temporarily. For example, Zhang and Gawarkiewicz (2015) studied satellite and in situ observations of what they termed "Pinocchio's Nose Intrusion": an along-shelf gravity current carrying warm salty Gulf Stream water downstream in the coastaltrapped wave sense along the Mid-Atlantic Bight shelf break. Such a feature was previously noted in the numerical experiments of Shi and Nof (1993) and Oey and Zhang (2004) and observed by Lee and Brink (2010). The "intrusion" was forced by a Gulf Stream warm-core ring interacting with the shelf-slope topography and was confined to a small region near the shelf break. The ring advected onshore a density front usually present at this shelf break-generally termed a "shelfbreak front" (Linder and Gawarkiewicz 1998). In one dramatic example, Cenedese et al. (2013) observed a warm-core 


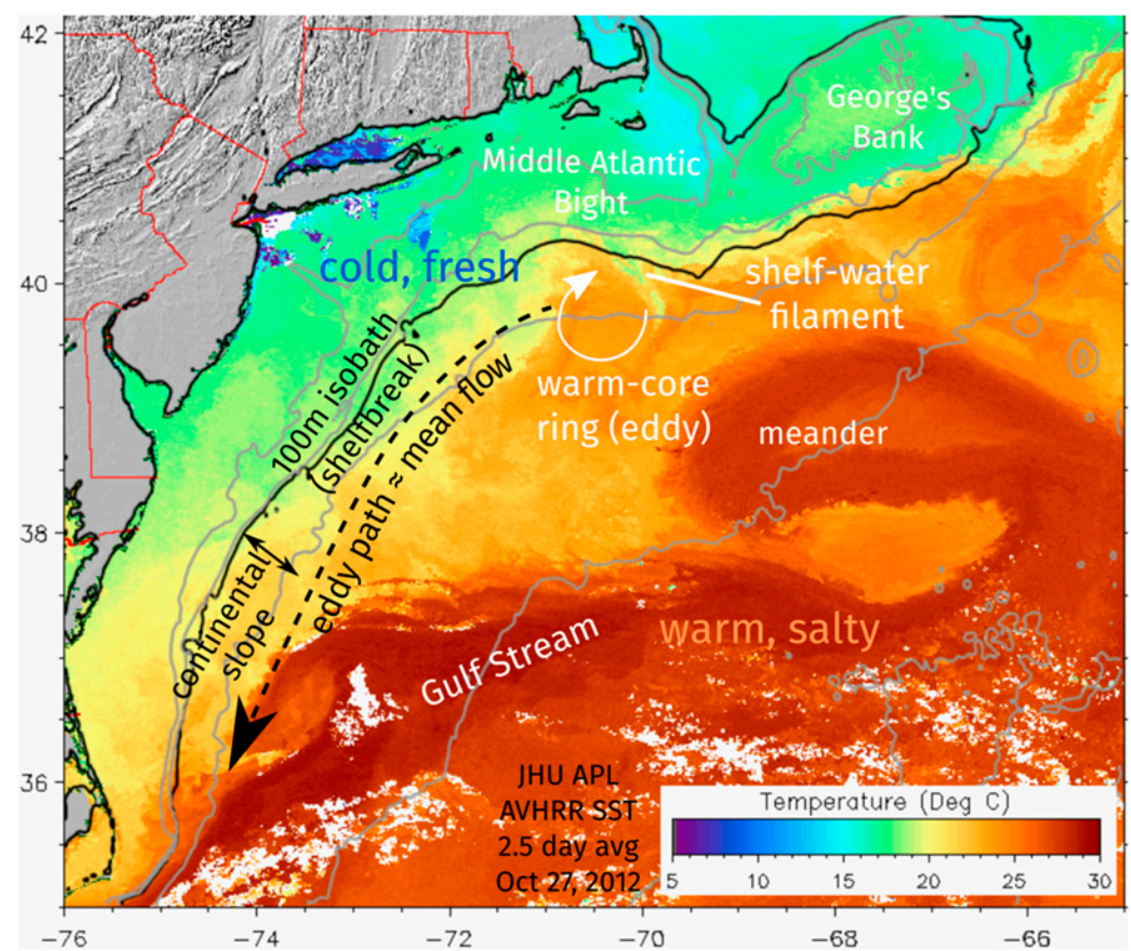

FIG. 1. In this modified AVHRR image from Johns Hopkins University Applied Physics Laboratory, a Gulf Stream warm-core ring transports a filament of shelf-water offshore. Topographic contours are overlaid in gray (50-, 80-, 2000-, 4000-, and 5000-m isobaths). The solid black contour is the $100-\mathrm{m}$ isobath, generally considered the shelf break.

ring forcing the reversal of the baroclinic jet that balances this shelfbreak density front. Such dramatic changes need not always occur. Depending on their trajectory, the influence of warm-core rings can be solely limited to the upper slope (Ramp et al. 1983; Beardsley et al. 1985).

In this paper, we examine the flow field on a sloping shelf forced by a translating deep-water mesoscale anticyclonic eddy present at the shelf break. As in the flat shelf study of Cherian and Brink (2016), we use a series of idealized primitive equation numerical simulations in which an anticyclonic eddy initialized in deep water moves toward and interacts with shelf-slope topography to the south. There we studied the fate of shelf-water parcels once they leave the shelf and presented a recipe for estimating the magnitude of the cross-shelfbreak transport. We expect the background potential vorticity gradient associated with the bottom slope to substantially influence the structure of the shelf's response to eddy forcing at the shelf break. Accordingly, our focus here is the flow field on a sloping shelf. We tackle the following questions: 1) Where in the along- and cross-isobath directions does the exported shelf water originate, 2) to what extent can eddy water penetrate onto the shelf, 3 ) are the cross-shelfbreak flows vertically uniform or vertically sheared (i.e., is shelf water exported primarily from near the surface or from the bottom), and 4) does the magnitude of offshore transport of shelf water depend on the shelf slope? We begin by describing the model.

\section{Experiment design}

The experiments are near identical to those in Cherian and Brink (2016), so nearly all the material below is repeated with minor modifications so that this manuscript is self-contained. The only difference here is that the shelf is now sloping. We use an idealized configuration of the hydrostatic, primitive equation Regional Ocean Modeling System (ROMS; Shchepetkin and McWilliams 2005). It solves the equations (subscripts represent differentiation and $\left.\nabla=\partial_{x} \hat{\mathbf{i}}+\partial_{y} \hat{\mathbf{j}}\right)$ : 
TABLE 1. Terminology used in this paper.

\begin{tabular}{ll}
\hline \multicolumn{1}{c}{ Term } & \multicolumn{1}{c}{ Definition } \\
\hline$\left(L_{0}, L^{z}\right)$ & Gaussian horizontal and vertical scales of the eddy \\
{$\left[x_{\mathrm{cen}}(t), y_{\mathrm{cen}}(t)\right]$} & Location of the eddy's center (SSH maximum) \\
$V_{0}$ & Maximum azimuthal velocity in eddy \\
$f_{0}$ & Coriolis frequency \\
$Y_{\mathrm{sb}}, H_{\mathrm{sb}}$ & Shelfbreak location and depth \\
$r_{f}$ & Linear bottom drag coefficient $\left(\mathrm{m} \mathrm{s}^{-1}\right)$ \\
$\lambda$ & $H_{\mathrm{sb}} / L^{z}$, nondimensional shelfbreak depth \\
$\alpha_{\mathrm{sh}}, \alpha_{\mathrm{sl}}$ & Bottom slope magnitude on shelf and slope \\
$L_{\mathrm{sh}}$ & Shelf width \\
$S_{\mathrm{sh}}, S_{\mathrm{sl}}$ & shelf and slope Burger numbers $(\alpha N / f)$, \\
$\mathrm{Ro}$ & Rossby number $V_{0} /\left(f_{0} L_{0}\right)$ \\
$\mathrm{Ek}$ & Ekman number $r_{f} /\left(f_{0} H_{\mathrm{sb}}\right)$ \\
$\beta$ & $d f / d y$ \\
$\beta_{\mathrm{sh}}$ & Topographic $\beta,\left(f_{0} / H_{\mathrm{sb}}\right) \alpha_{\text {sh }}$ \\
$C, E$ & Passive tracers: cross-shelf dye and eddy-water dye \\
$L_{\beta}$ & $\sqrt{V_{0} / \beta_{\text {sh }}}$ \\
$C_{\mathrm{min}}$ & Minimum value of cross-shelf dye crossing the shelf break at time instant $t$ \\
$C_{\mathrm{mean}}(y)$ & Time- and depth-averaged cross-shelf dye field at $y$ \\
$\left(u^{\mathrm{bot}}, v^{\mathrm{bot}}\right)$ & Bottom velocity \\
$\zeta$ & Relative vorticity \\
$\mathrm{BC}$ & Baroclinicity, a measure of vertical shear in flow velocity \\
\hline
\end{tabular}

$$
\begin{gathered}
u_{t}+u u_{x}+v u_{y}+w u_{z}-f v=-\frac{1}{\rho_{0}} p_{x}+\left(A_{v} u_{z}\right)_{z}+\nabla \cdot\left(A_{H} \nabla u\right)+\underbrace{\nabla \cdot \sqrt{A_{B}} \nabla\left(\nabla \cdot \sqrt{A_{B}} \nabla u\right)}_{\text {biharmonic viscosity }}, \\
v_{t}+u v_{x}+v v_{y}+w v_{z}+f u=-\frac{1}{\rho_{0}} p_{y}+\left(A_{v} v_{z}\right)_{z}+\nabla \cdot\left(A_{H} \nabla v\right)+\nabla \cdot \sqrt{A_{B}} \nabla\left(\nabla \cdot \sqrt{A_{B}} \nabla v\right),
\end{gathered}
$$

$$
\begin{aligned}
0 & =-p_{z}-\rho g, \\
u_{x}+v_{y}+w_{z}= & 0, \quad \text { and } \\
\rho_{t}+u \rho_{x}+v \rho_{y}+w \rho_{z}= & \left(\kappa_{v} \rho_{z}\right)_{z}+\nabla \cdot\left(\kappa_{H} \nabla \rho\right) \\
& +\underbrace{\nabla \cdot \sqrt{\kappa_{B}} \nabla\left(\nabla \cdot \sqrt{\kappa_{B}} \nabla \rho\right)}_{\text {biharmonic diffusivity }} .
\end{aligned}
$$

Coordinate variables $(x, y, z)$ define a right-handed Cartesian coordinate system with $x$ being along isobath, $y$ cross isobath, and $z$ depth. In Eqs. $(1-3,5)$, $\rho_{0}=1025 \mathrm{~kg} \mathrm{~m}^{-3}$ and $\rho(x, y, z, t)$ is the density anomaly. The model domain is a $\beta$ plane with Coriolis frequency $f=f_{0}+\beta y$. The main elements of the problem (viz., shelf-slope topography, anticyclonic eddy, and ambient stratification) are all reduced to the simplest possible form.

The topography is constructed using three straight lines to bound the shelf, the continental slope, and the deep ocean, respectively. The deep ocean bottom is always flat. A four-point running mean is applied six times to smooth the topography at the shelf break and slope break. The term "shelf break" refers to the intersection of the shelf and continental slope, while "slope break" refers to the intersection of the continental slope and the flat-bottomed deep ocean.

Salinity is always a constant, and the linear equation of state involves potential temperature only. The eddy is a radially symmetric, surface-intensified, Gaussian temperature anomaly superimposed on background stratification $\bar{\rho}$ as follows:

$$
T_{\text {edd }}=T_{\text {amp }} \exp \left[-\left(r / L_{0}\right)^{2}-\left(z / L^{z}\right)^{2}\right] .
$$

Here $r$ is the radial distance from the eddy's center. The initial horizontal length scale $L_{0}$ is specified and the vertical scale is $L^{z}=\left(f_{0} L_{0}\right) /(N \sqrt{2})$, where $L_{0} / \sqrt{2}$ is the radius to maximum velocity (All quantities used in this paper are summarized in Table 1.). The density anomaly is balanced by a cyclo-geostrophic velocity field determined after prescribing zero velocity at the bottom. The ambient buoyancy frequency $N$ is always constant. 


\section{Surface cross-shelf dye $(\mathrm{km})$}
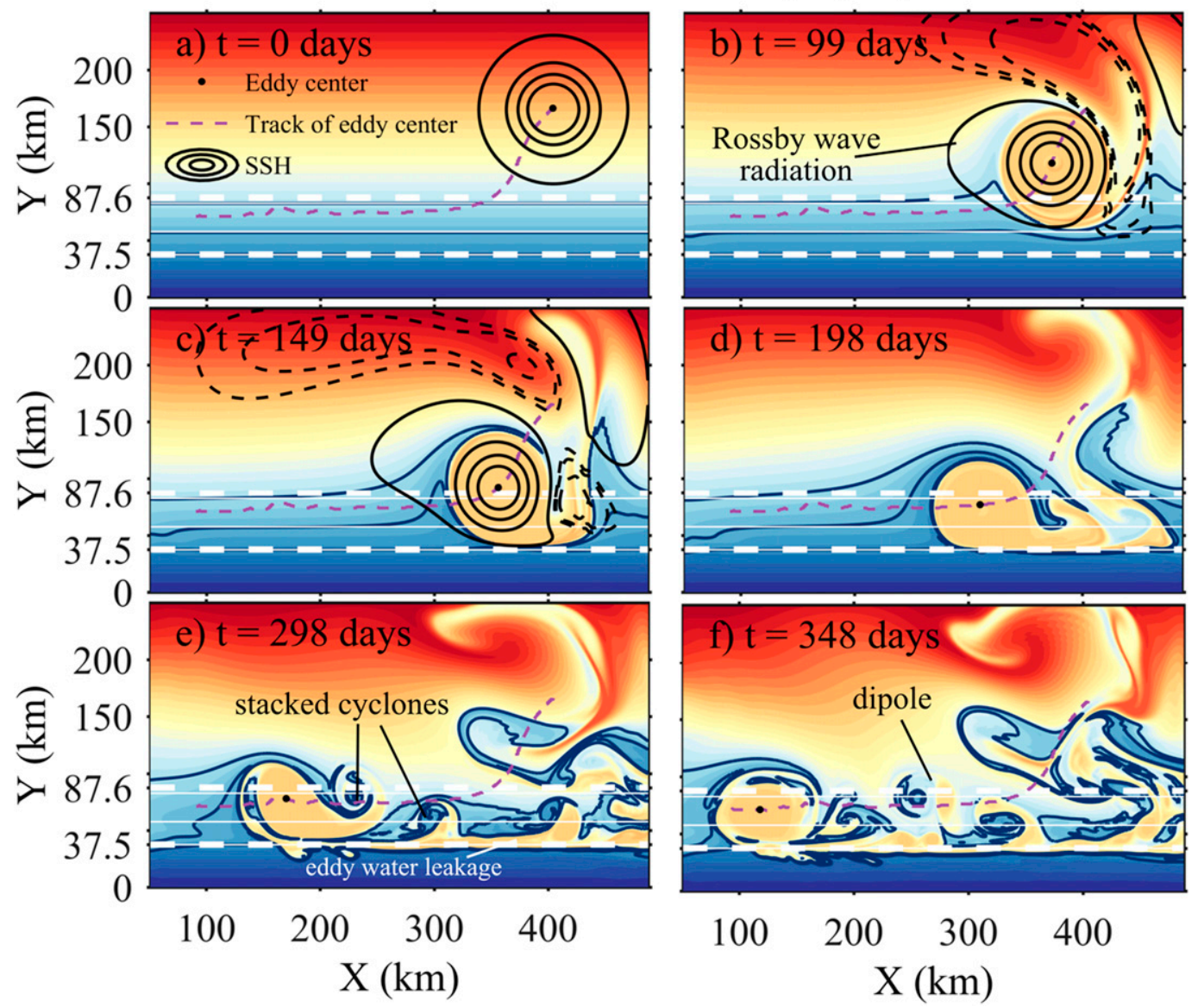

FIG. 2. Snapshots of the cross-shelf dye field at the surface. Black contours are SSH, and dashed contours indicate negative values. Thick white dashed lines mark the shelf and slope break. The evolution is just as in the flat shelf simulations of Cherian and Brink (2016).

The eddy always starts in deep water far from the topography, approximately one deformation radius away from the slope break (Fig. 2), so that its initial evolution is as over a flat-bottomed ocean (verified using a flat-bottom simulation). We let the eddy adjust to the $\beta$ plane in deep water before it impacts the slope, unlike previous studies where the eddy is initialized over the slope (e.g., Oey and Zhang 2004; Zhang and Gawarkiewicz 2015).

Isolated anticyclonic eddies move southwestward on a $\beta$ plane (McWilliams and Flierl 1979; Mied and Lindemann 1979; Nof 1983; Early et al. 2011), making the eddy translate across isobaths without a crossisobath background flow. The southwestward motion renders two coastal locations moot: for a coast at the north or east, the eddy will move away from the shelf break. So, the topography must be placed at either the western or southern boundary of the domain for the eddy to encounter it. All experiments described here use topography with a southern coast. With open eastern and western boundaries, this configuration allows westward-propagating Rossby waves radiated by the eddy (Flierl et al. 1983) to exit the domain, allowing the eddy to interact with undisturbed shelf-slope waters. A western coast configuration traps Rossby wave momentum that results in large flow features spinning up over the slope prior to the eddy's arrival (Cherian and Brink 2016, section 9a). Upon impact, the eddy then translates northward toward these flow features. Our goal here is to study the shelf-edge flows that result from the interaction of an isolated eddy with undisturbed shelf-slope waters, and such northward translation is not desirable. Qualitatively, our results hold for both orientations because the shelf-edge flows of interest have horizontal length scales too small to be influenced by the planetary $\beta$ plane. Quantitatively, the diagnosed length scales of shelf flows only differ by two to three grid points when comparing a simulation with a southern coast to that with a western coast (all other simulation parameters being identical). In addition, the background topographic vorticity gradient on the shelf $\beta_{\mathrm{sh}}$ is 
TABLE 2. Simulation parameters.

\begin{tabular}{|c|c|c|c|c|c|c|c|c|c|c|c|c|}
\hline & $\mathrm{Rh}$ & Ro & $\beta\left(10^{-10} \mathrm{~m}^{-1} \mathrm{~s}^{-1}\right)$ & $\beta_{\mathrm{sh}}\left(10^{-10} \mathrm{~m}^{-1} \mathrm{~s}^{-1}\right)$ & $\phi_{o}$ & $\lambda$ & $S_{\mathrm{sl}}$ & $S_{\mathrm{sh}}$ & $L_{\beta}(\mathrm{km})$ & $L_{\mathrm{def}}(\mathrm{km})$ & $r_{f}\left(10^{-4} \mathrm{~m} \mathrm{~s}^{-1}\right)$ & $\overline{L_{\text {atw }}(\mathrm{km})}$ \\
\hline ew-04 & 3.06 & 0.10 & 0.60 & 0.00 & 0.00 & 0.20 & 1.50 & 0.00 & 0 & 4 & & \\
\hline ew-8040 & 3.08 & 0.10 & 0.60 & 1.52 & 0.02 & 0.19 & 1.50 & 0.01 & 34 & 4 & & \\
\hline ew-8041 & 3.09 & 0.10 & 0.60 & 7.83 & 0.08 & 0.19 & 1.50 & 0.05 & 12 & 4 & & \\
\hline ew-8042 & 3.06 & 0.10 & 0.30 & 8.03 & 0.18 & 0.18 & 1.50 & 0.10 & 17 & 7 & & \\
\hline ew-82342 & 7.34 & 0.10 & 0.10 & 1.92 & 0.64 & 0.54 & 1.00 & 0.10 & 21 & 16 & & \\
\hline ew- 82343 & 7.34 & 0.10 & 0.10 & 2.84 & 0.98 & 0.55 & 1.00 & 0.15 & 17 & 16 & & \\
\hline ew-34 & 11.72 & 0.10 & 0.15 & 0.00 & 0.00 & 0.15 & 1.50 & 0.00 & 0 & 3 & & \\
\hline ew-8341 & 13.19 & 0.11 & 0.15 & 7.83 & 0.08 & 0.14 & 1.50 & 0.05 & 12 & 3 & & \\
\hline ew-8350-2 & 14.93 & 0.19 & 0.15 & 0.00 & 0.00 & 0.17 & 3.06 & 0.00 & 0 & 7 & & \\
\hline ew-8351-2 & 14.93 & 0.19 & 0.15 & 2.25 & 0.10 & 0.17 & 3.06 & 0.05 & 23 & 7 & & \\
\hline ew-8352-2 & 14.93 & 0.19 & 0.15 & 4.70 & 0.20 & 0.16 & 3.06 & 0.10 & 16 & 7 & & \\
\hline ew-8352 & 17.23 & 0.15 & 0.035 & 1.82 & 0.22 & 0.28 & 1.00 & 0.10 & 24 & 11 & & \\
\hline ew-8342-2 & 5.93 & 0.08 & 0.15 & 4.70 & 0.50 & 0.19 & 3.06 & 0.10 & 11 & 7 & & \\
\hline ew-8380 & 18.90 & 0.16 & 0.050 & 0.00 & 0.00 & 0.22 & 1.00 & 0.00 & 0 & 9 & & \\
\hline ew-8381 & 18.90 & 0.16 & 0.050 & 1.68 & 0.07 & 0.22 & 1.00 & 0.05 & 35 & 9 & & \\
\hline ew-8384 & 18.90 & 0.17 & 0.050 & 5.02 & 0.22 & 0.22 & 1.00 & 0.15 & 20 & 9 & & \\
\hline ew-8385 & 18.58 & 0.16 & 0.050 & 6.39 & 0.31 & 0.23 & 1.00 & 0.20 & 18 & 10 & & \\
\hline ew-8383 & 13.44 & 0.12 & 0.050 & 3.28 & 0.51 & 0.37 & 1.00 & 0.15 & 20 & 14 & & \\
\hline ew-8392 & 31.82 & 0.24 & 0.035 & 2.13 & 0.48 & 0.22 & 3.00 & 0.20 & 28 & 19 & & \\
\hline ew-583411 & 13.19 & 0.11 & 0.15 & 7.83 & 0.05 & 0.15 & 1.50 & 0.05 & 12 & 3 & 30 & 21 \\
\hline ew-583413 & 13.19 & 0.11 & 0.15 & 7.83 & 0.05 & 0.15 & 1.50 & 0.05 & 12 & 3 & 5.0 & 123 \\
\hline ew-583414 & 13.19 & 0.11 & 0.15 & 7.83 & 0.05 & 0.15 & 1.50 & 0.05 & 12 & 3 & 1.0 & 617 \\
\hline ew-583415 & 13.19 & 0.11 & 0.15 & 7.83 & 0.05 & 0.15 & 1.50 & 0.05 & 12 & 3 & 0.50 & 1234 \\
\hline
\end{tabular}

usually a factor of 10-1000 larger than planetary $\beta$ (cf. $\beta_{\mathrm{sh}}$ and $\beta$ in Table 2; $\beta_{\mathrm{sh}} / \beta \sim 100$ for the Mid-Atlantic Bight). Thus, in realistic contexts, the shelf's topographic $\beta$ plane is the primary background potential vorticity gradient. Coastal orientation then ceases to matter and the primary effect of the planetary $\beta$ plane is to make the eddy self-advect itself toward the topography.

The coastal boundary is a free-slip wall and the other three are open. Open boundary conditions used are an explicit Chapman condition for the free surface (gravity wave radiation; explicit in Chapman 1985), a modified Flather condition for 2D momentum (Mason et al. 2010), and a combined radiationnudging condition for tracers and 3D momentum (Marchesiello et al. 2001). We use sponge layers to prevent noise at the open boundary from contaminating the solution. These are $50-\mathrm{km}$-wide (40 points) regions with lateral Laplacian viscosity $A_{H}$ linearly increasing from 0 to $50 \mathrm{~m}^{2} \mathrm{~s}^{-1}$ and lateral Laplacian diffusivity $\kappa_{H}=0-5 \mathrm{~m}^{2} \mathrm{~s}^{-1}$.

For computational efficiency, a hyperbolic tangent function is used to stretch the horizontal grid spacing near the sponge layers at the open boundaries. Horizontal spacing is always at least $1 \mathrm{~km}$ and less than $2.5 \mathrm{~km}$. Our diagnostics are not very sensitive to changes in grid spacing. In the vertical, we distribute 72 grid points such that vertical grid spacing is smallest near the surface and largest near the bottom $(0.6-25 \mathrm{~m})$. A density-Jacobian-based algorithm (Shchepetkin and
McWilliams 2003) reduces pressure gradient error. ${ }^{1}$ We use biharmonic lateral viscosity $\left(A_{B}=4.4 \times 10^{6}-3 \times\right.$ $\left.10^{8} \mathrm{~m}^{4} \mathrm{~s}^{-1}\right)$ and diffusivity $\left(\kappa_{B}=1.2 \times 10^{3}-8 \times 10^{4} \mathrm{~m}^{4} \mathrm{~s}^{-1}\right)$ along sloping vertical coordinate surfaces ${ }^{2}$ to control noise outside the sponge layers. The values scale with gridcell size. The Laplacian coefficients $A_{H}, \kappa_{H}$ are 0 outside the sponge layers. When used, the bottom friction term is linear with coefficient $r_{\mathrm{f}}$ :

$$
\tau^{\text {bot }}=\rho_{0} r_{f}(u, v)
$$

\section{Diagnostics}

\section{a. Topography}

The topography is characterized by the following parameters. The $\lambda=H_{\mathrm{sb}} / L^{z}$ is a nondimensional measure of the shelfbreak depth $H_{\mathrm{sb}}$ relative to the eddy's vertical scale $L^{z}$. A slope Burger number is defined as $S=\alpha N / f_{0}$ with $\alpha=d H / d y$ and subscripts sh and sl referring to the continental shelf and continental slope, respectively. Topographic $\beta$ for the shelf is defined as $\beta_{\mathrm{sh}}=\alpha_{\mathrm{sh}} f_{0} / H_{\mathrm{sb}}$. Finally, $Y_{\mathrm{sb}}$ will refer to the $y$ location of the shelf break.

\footnotetext{
${ }^{1}$ We use the ROMS option DJ_GRADPS.

${ }^{2}$ These are referred to as $s$ surfaces in ROMS terminology.
} 


\section{b. Eddy diagnostics}

The eddy is tracked using the method described in Chelton et al. (2011) with slight modifications. The method detects a largest possible simply connected region within a closed SSH contour containing an SSH maximum (or minimum for a cyclone). The eddy's center $\left[x_{\text {cen }}(t), y_{\text {cen }}(t)\right]$ is defined as the location of the SSH maximum within the detected region, where the square brackets indicate a position vector. The core of the eddy is defined as the zero relative vorticity contour within the detected SSH boundary. Despite concerns raised by Beron-Vera et al. (2013) and others, the detected eddy boundary does enclose material that is trapped over large space and time scales and is deemed to be a useful diagnostic (e.g., Fig. 2; Early et al. 2011).

Time series of the eddy's velocity and length scales are obtained by assuming that the eddy's density anomaly remains a Gaussian in all dimensions throughout the simulation. The corresponding balanced geostrophic velocity field, with maximum velocity $V_{0}$, is described by

$$
V=(\sqrt{2 e}) V_{0}\left(r / L_{0}\right) e^{-\left(r / L_{0}\right)^{2}} .
$$

Equation (8) is fit to the eddy's surface velocity along a horizontal line in the along-isobath direction. The fit determines the eddy's maximum azimuthal velocity $V_{0}$ and its Gaussian length scale $L_{0}$ at the latitude of the eddy's center. These metrics, though based on approximations about eddy shape, are much less sensitive than estimating average velocities along an identified contour or the contour's equivalent radius. A Gaussian fit, $\exp \left[-\left(z / L^{z}\right)^{2}\right]$, to the vertical profile of the temperature anomaly at the eddy's center diagnoses its vertical scale $L^{z}$. The eddy's Rossby number is defined as $\operatorname{Ro}(t)=V_{0}(t) /\left[f_{0} L_{0}(t)\right]$. The eddy's eastern and western edges are defined as $x_{\text {cen }}(t) \pm L_{0}(t)$, respectively.

\section{c. Time interval for averaging}

We will examine flow fields and scales averaged over a time interval when the eddy is interacting with the shelf and slope. As in Cherian and Brink (2016), we define that time interval using the cumulative integral of the cross-shelfbreak flux of shelf water. We will use the notation $\left[t_{\text {start }}, t_{\text {stop }}\right]$, where $t_{\text {start }}\left(t_{\text {stop }}\right)$ are the times at which the accumulated shelf-water volume transported across the shelf break is $5 \%$ ( $95 \%$ ) of its value at the end of the simulation.

\section{d. Vertical structure of flows}

The nondimensional parameter, given by

$$
\mathrm{BC}=\operatorname{median}\left(\frac{\left|U_{s}-U_{b}\right|}{\left|U_{s}\right|}\right),
$$

quantifies the extent to which a velocity field is vertically sheared (i.e., baroclinic). The $U_{s}$ and $U_{b}$ are velocities at the surface and 10 points off the bottom, respectively. The definition prevents $\mathrm{BC}$ from being substantially influenced by the bottom boundary layer in simulations with bottom friction. For barotropic flows, $U_{s}=U_{b}$ and $\mathrm{BC}=0$, whereas for more baroclinic flows, $U_{s} U_{b}<0$ or $U_{b}=0$ and $\mathrm{BC} \geq 1$. We restrict the calculation to only include cells with $\left|U_{s}\right| \geq 0.2 \max \left(\left|U_{s}\right|\right)$, the spatial maximum being calculated at each time instant. We will use this metric separately with along- and crossshelf velocities over the shelf, that is, with $U \equiv u$ and $U \equiv v$, respectively. When a time series of $\mathrm{BC}$ is required (i.e., in section 7), the median is applied in $(x, y)$.

\section{e. Water masses}

There is no shelfbreak front, so shelf and slope waters are indistinguishable in density. Instead, each water parcel is tagged with its initial latitude using a passive tracer termed the "cross-shelf dye": $C(x, y, z, t) ; C(x, y, z, t=0)=y$. This dye traces shelf water [water parcels that initially start south of the shelfbreak $C<Y_{\mathrm{sb}}$, the latitude of the shelf break] and slope water (parcels that are initially between the shelf- and slope-break).

We use a second passive tracer $E(x, y, z, t)$ to track water parcels in the eddy. This passive tracer is initialized with value 1 where the temperature anomaly [Eq. (6)] is greater than some small value and 0 elsewhere. In practice, not all of the dye with value 1 is carried with the eddy, but this conservative initial distribution lets us identify an eddy core that transports mass over long spatial and time scales. In addition, the eddy also homogenizes the cross-shelf dye within it, letting us distinguish it from the surrounding water. We will define water parcels with $E>0.7$ to be eddy water. Thus the shelf-water and eddy-water fronts are defined as $C(x, y, z, t)=Y_{\mathrm{sb}}$ and $E(x, y, z, t)=0.7$.

\section{Qualitative aspects}

\section{a. A typical simulation}

The evolution of an anticyclone of radius $25 \mathrm{~km}$, vertical scale $400 \mathrm{~m}$, and Rossby number 0.1 is visualized using the cross-shelf dye field in Fig. 2. The slope Burger number for the continental slope is 1 and that of the shelf is 0.05 . The shelfbreak depth is $50 \mathrm{~m}$ and there is no bottom friction.

The eddy evolves as described in Cherian and Brink (2016) for simulations with a flat shelf. It moves southwestward while radiating Rossby waves, evidenced by the westward spreading of SSH contours in Fig. 2b. 


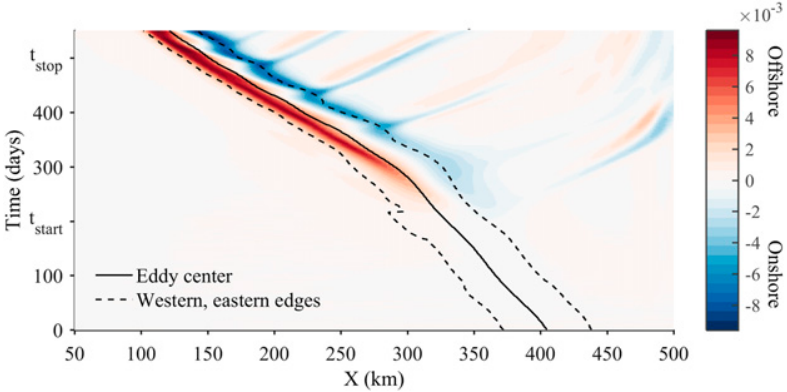

FIG. 3. The $x-t$ Hovmoeller diagram of depth-averaged crossshelf velocity at the shelf break. Offshore flow is in red and onshore flow in blue. Solid and dashed lines, respectively, mark the eddy's center and its edges in the along-isobath direction. Both the offshore and onshore flow are largest near the eddy. The alongisobath scale of both the outflow and the inflow is approximately an eddy radius. Small-scale anticyclones formed by the instability of the eddy-water leakage propagate downstream in the coastal trapped wave direction.

When its edge reaches the shelf break, the eddy translates westward along an isobath, continuously leaking mass in an along-shelfbreak jet (Figs. 2c-f), termed the "leakage" by Shi and Nof (1993) and Pinocchio's Nose Intrusion by Zhang and Gawarkiewicz (2015). The along-isobath scale of both off- and onshore flow at the shelf break is an eddy radius; apparent in Fig. 3 - the $x-t$ Hovmöller diagram of depth-averaged cross-isobath flow at the shelf break. Figure 3 does not distinguish between eddy and shelf waters. The solid black line is the eddy center and the dashed lines are the eddy's western and eastern edges.

The eddy exports shelf water across the shelf break while advecting slope and eddy waters on to the shelf. Initially, the shelf water is exported as a filament, termed a "streamer" in the literature (Fig. 2d). Later, the exported shelf water forms cyclones that then combine with eddy water in the leakage to form dipoles (Figs. 2e,f). These cyclones are "stacked"-they contain shelf water stacked over eddy water with cyclonic vorticity throughout. Cherian and Brink (2016) described their formation as a consequence of instability waves excited on the eddy's potential vorticity gradient when it impacts the continental slope. These consist of a growing cyclonic anomaly propagating on the eddy's edge and a growing anticyclonic anomaly propagating in the eddy's core. The cyclonic anomaly traps shelf water advected over it as it grows to finite amplitude and ultimately forms a "stacked cyclone." Cherian and Brink (2016) explain this process in more detail. Here we study the shelf flow field forced by the eddy. A shelf volume budget and the schematized flow field in Fig. 4 will provide useful context for the rest of our investigation.

\section{b. Volume budget for the shelf}

A volume budget for shelf water may be constructed in two ways. First, consider shelf water as water parcels in a fixed geographic volume bounded by the shelf break and the coast to the south. As expected from the linear physics described in Chapman and Brink (1987), the eddy's influence on the shelf is largely to the east (i.e., downstream of the eddy in the coastaltrapped wave sense; Fig. 4). The net offshore volume flux across the shelf break is compensated by an alongshelf input to the shelf at the open eastern boundarysolid and dashed black lines nearly balance in the shelf volume budget (Fig. 5). This approximate balance holds regardless of shelf slope magnitude and orientation (southern or western coast $^{3}$ ). The eastern boundary is special in this configuration because it is the "downstream" boundary, relative to the propagation direction of coastal-trapped, or Kelvin, waves. The volume of water on the shelf, again defined geographically, does not change appreciably throughout the simulation.

Second, consider shelf water to be water parcels defined using a water property such as salinity. The simulations here lack salinity, so shelf water is defined as parcels with initial cross-shelf dye value $<Y_{\mathrm{sb}}$ (i.e., these are water parcels that started on the shelf at $t=0$ ). This definition of shelf water is used for the rest of the paper. The eddy exports shelf water, so defined, across the shelf break. To compensate, an along-shelf "supply jet" directed westward (upstream) toward the eddy supplies shelf water from the open eastern (downstream) boundary (Fig. 4). Again up- and downstream are directions relative to the coastal-trapped- or Kelvin-wave propagation direction. The compensation is always incomplete: the cross-shelf export of shelf water is larger than the along-shelf import of shelf water by about $30 \%$ in Fig. 5 (cf. solid and dashed blue lines). The rest is compensated by the onshore transport of eddy and slope waters. There is thus permanent export of shelf water. Shelf-water parcels that cross the shelf break never return to the shelf; they are trapped in the stacked cyclones described in Cherian and Brink (2016). Further, the along-shelfbreak eddy-water leakage (or intrusion) also prevents exported shelf-water parcels returning to the shelf (Figs. 2d-f). Simulations with a western coast exhibit analogous behavior: a northward along-shelf jet supplies shelf water from downstream (now south) of the eddy (Cherian and Brink 2016). Such behavior

\footnotetext{
${ }^{3} \mathrm{We}$ rely on western coast simulations from Cherian and Brink (2016).
} 


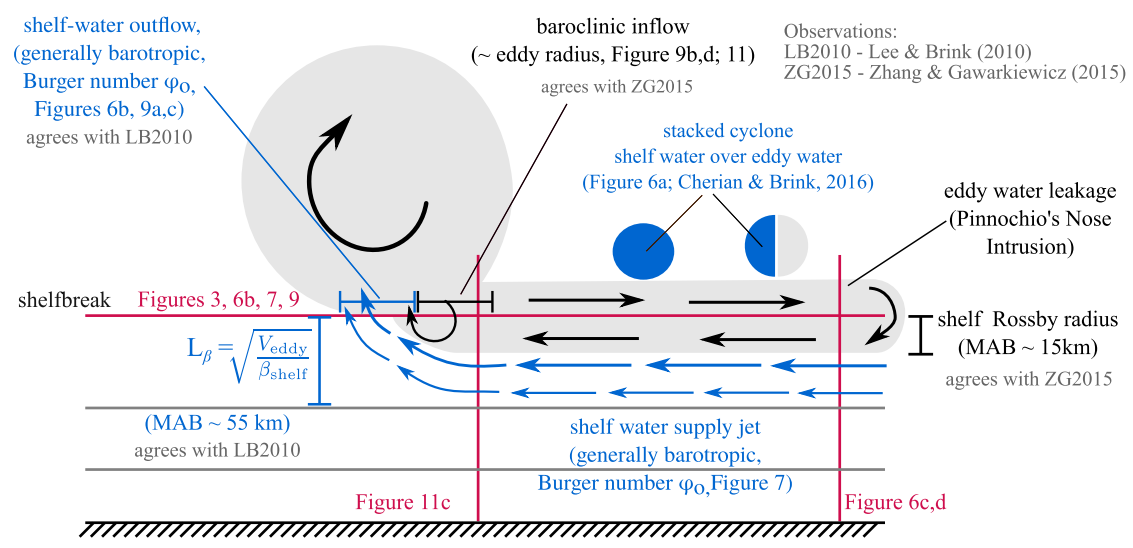

FIG. 4. Schematic flow field forced by a deep-water eddy at the shelf break.

agrees with the linear simulations of Chapman and Brink (1987).

\section{c. Instantaneous flow field}

The instantaneous flow fields over the shelf exhibit significant complexity (see snapshots at $t=300$ days in Fig. 6). Figure $6 \mathrm{~b}$ is a snapshot of the cross-shelfbreak flow with density contours overlaid in black. The blue contours bound water parcels that started inshore of the shelf break. The offshore flow of shelf water is concentrated near the eddy $(x \approx 150 \mathrm{~km})$. There is a strong density front between eddy and shelf waters and associated vertical shear. This shear largely affects eddywater parcels, and the offshore flow of shelf water is largely barotropic $(\mathrm{BC} \sim 0.1)$. In contrast, the onshore flux of eddy water is accomplished by a vertically sheared cross-shelf flow near the eddy $(\mathrm{BC} \sim 0.9 ; x \approx$ $180 \mathrm{~km}$ in Fig. 6b).

Figures $6 \mathrm{c}, \mathrm{d}$ are both cross-shelf sections of the alongshelf velocity at $x=350 \mathrm{~km}$; the only difference is that Fig. $6 \mathrm{c}$ focuses on the shelf while Fig. $6 \mathrm{~d}$ focuses on the outer slope. The along-shelf supply jet is evident at $y \approx$ $30 \mathrm{~km}$. Again the blue (red) contours indicate the shelf water (eddy water) boundary. Here too is a density front with the associated vertical shear largely experienced by eddy-water parcels. The along-shelf flow of shelf-water toward the eddy is largely barotropic and confined to a narrow region near the shelf break (into the plane, inshore of the blue contour; $y \approx 30 \mathrm{~km}$ in Figs. $6 \mathrm{c}$,d). This "supply jet" supplies the shelf water that is exported across the shelf break from the eastern boundary of the shelf. The eddy-water leakage is surface intensified

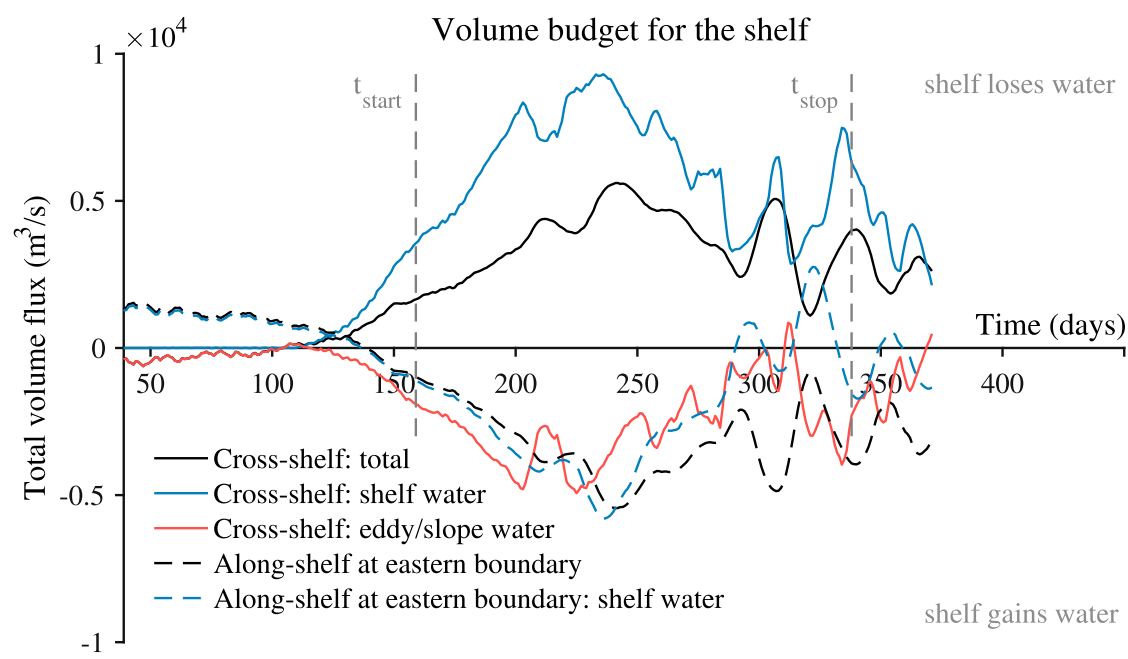

FIG. 5. Volume budget for the shelf, defined as a volume bounded by the two sponges, the coastal wall, and the shelf break. The export across the shelf break is compensated by an along-shelf jet moving water from the open eastern boundary into the shelf domain, as well as the onshore flow of eddy and slope waters. 

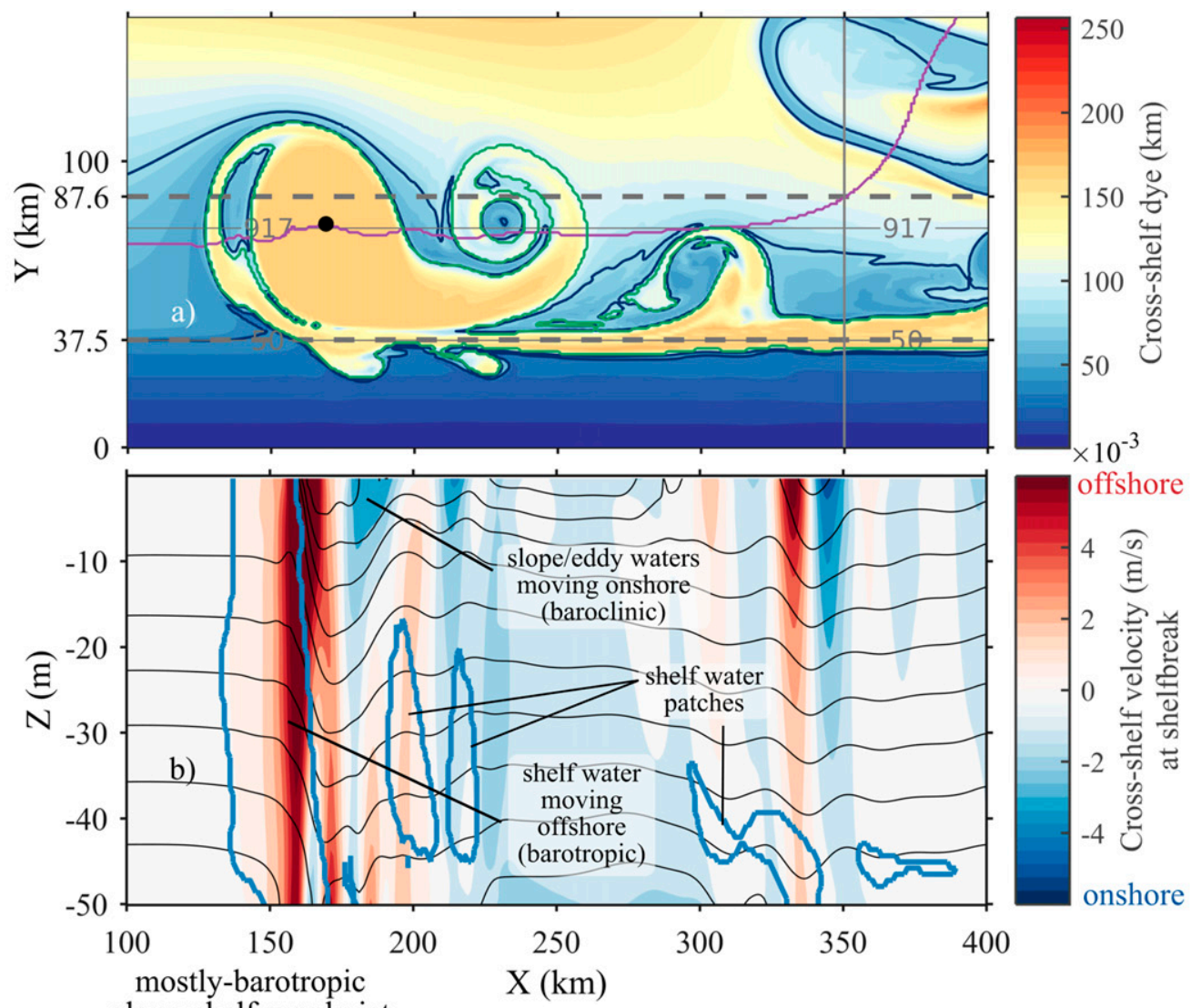
along-shelf supply jet (inshore of blue contour)
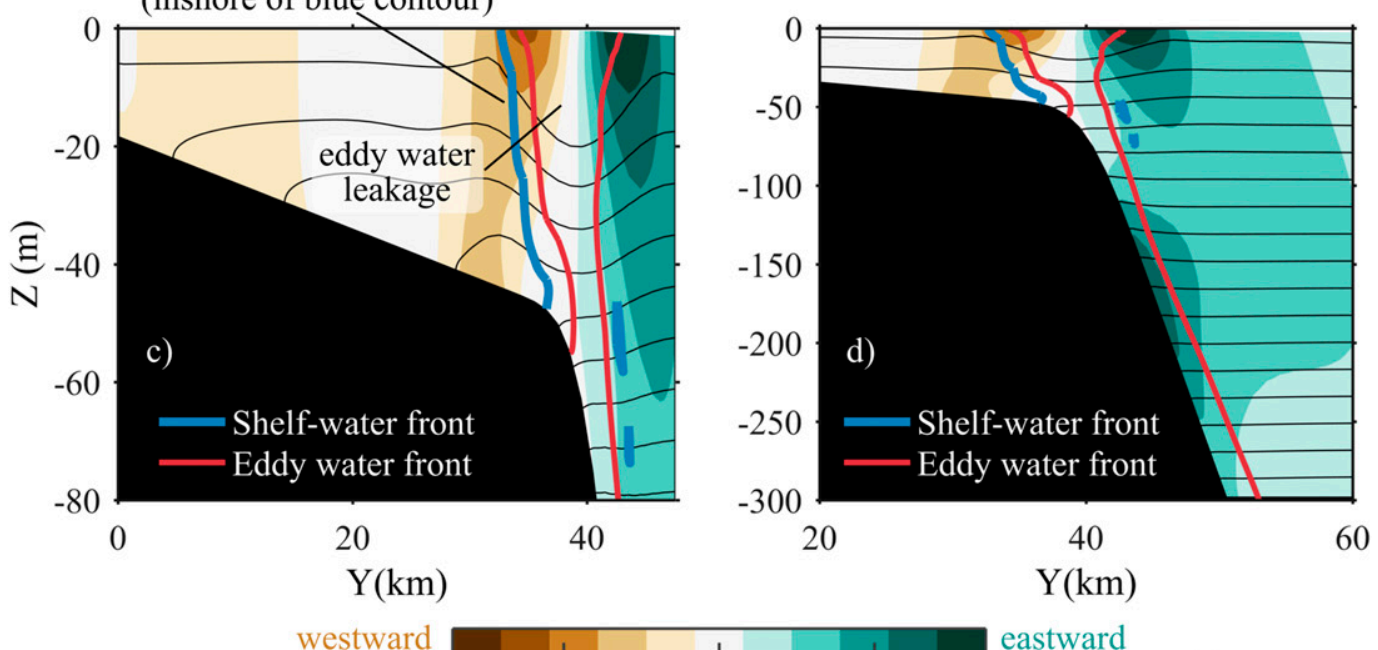
toward eddy

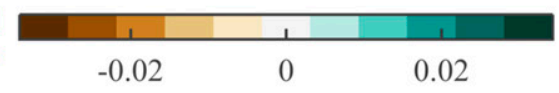

eastward away from eddy

Along-shelf velocity $(\mathrm{m} / \mathrm{s})$ at $\mathrm{x}=300 \mathrm{~km}$

FIG. 6. Instantaneous cross-sections at $t=300$ days from the simulation in Fig. 2. (a) The $x-y$ section of cross-shelf dye at the surface. (b) The $x-z$ section of cross-shelf velocity at the shelf break. (c),(d) The $y-z$ section of alongshore velocity at $x=350 \mathrm{~km}$, downstream of the eddy. Note different $x$-axis limits in (c) and (d).

(offshore of the blue contour; $y \approx 40 \mathrm{~km}$ in Figs. $6 \mathrm{c}, \mathrm{d}$ ). A near-bottom velocity maximum is evident over the upper slope (Fig. 6d). This "slope jet" transports eddy waters downstream in the coastal-trapped wave direction and has been studied in detail by Oey and Zhang (2004). 

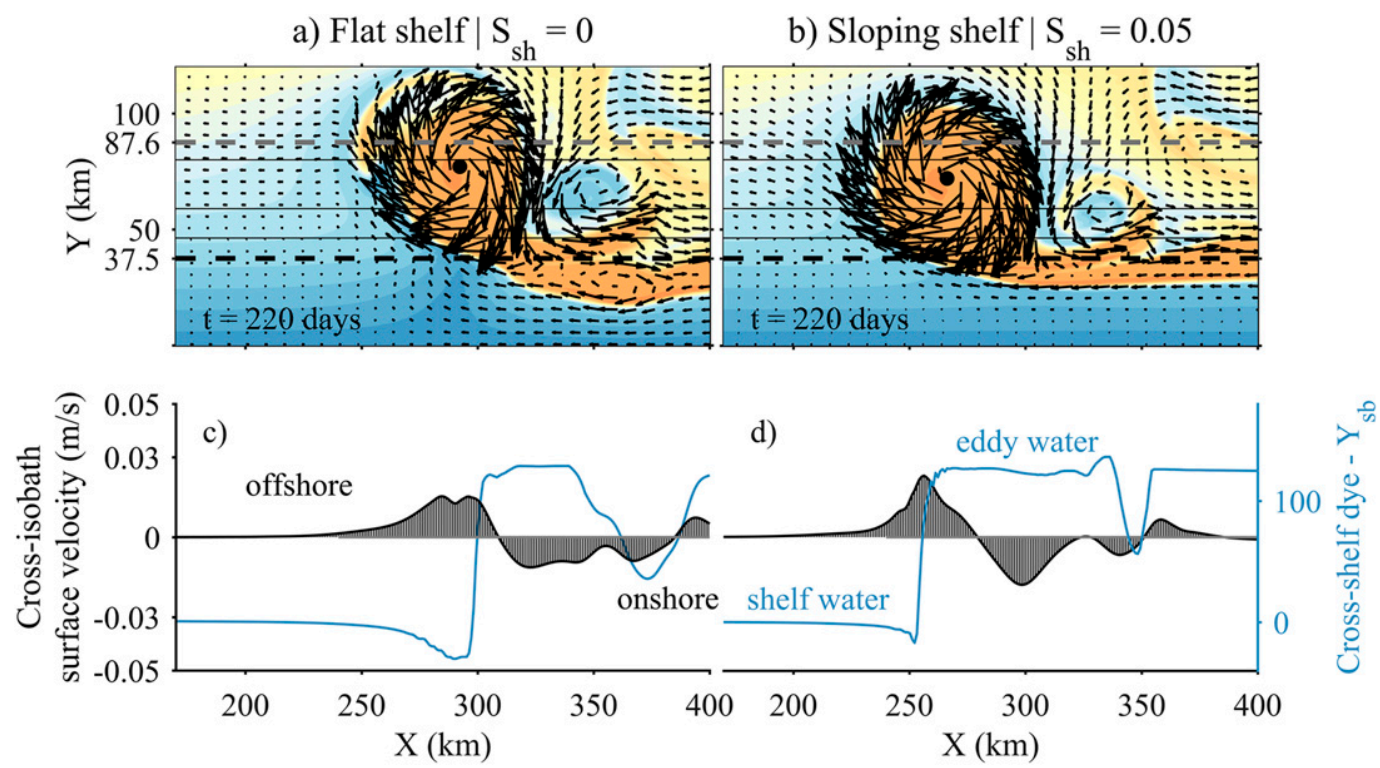

FIG. 7. Horizontal velocity vectors and cross-shelf dye at the surface for a flat shelf and a sloping shelf simulation. With a flat shelf, all of the shelf is forced into motion to supply the offshore flow at the shelf break. With a sloping shelf, there is a limit to the extent of the eddy's influence on the shelf.

\section{d. Comparison with flat shelf simulations}

When qualitatively compared to a flat shelf, a sloping shelf reduces both 1) the cross-isobath extent of the supply jet and 2) the magnitude of offshore shelf-water transport. Both effects are evident when comparing an instantaneous snapshot of the surface dye field and surface velocity vectors to an analogous snapshot from a simulation with a flat shelf (Fig. 7). Over a flat shelf, the supply jet exists across the whole shelf (Fig. 7a) while the sloping shelf reduces the supply jet's cross-isobath length scale. This limited crossisobath scale is an inertial length scale: $L_{\beta}=\sqrt{V_{0} / \beta_{\mathrm{sh}}}, V_{0}$ being an eddy velocity scale and $\beta_{\mathrm{sh}}=f_{0} / H_{\mathrm{sb}} \alpha_{\mathrm{sh}}$ the topographic beta for the shelf (see section $5 b$ ).

Time series of the cross-shelfbreak flux of shelf water are presented in Fig. 8a. The flux is calculated by integrating the cross-shelfbreak velocity field over shelfwater parcels identified as such using the cross-shelf dye field $\left[C\left(x, Y_{\mathrm{sb}}, z, t\right) \leq Y_{\mathrm{sb}}\right]$. Relative to a flat shelf simulation, a sloping shelf reduces both peak and average cross-shelfbreak flux magnitudes (cf. dark red and dark blue lines in Fig. 8a). We will argue that the reduced offshore flux is a consequence of the limited cross-shelf extent of the eddy's influence (section 6). First we study the horizontal and vertical scales of eddy-forced flows on the shelf.

\section{Flow on the shelf}

\section{a. Average cross-shelfbreak flows}

The eddy's effect on water properties and tracers over the outer shelf will depend on the vertical structure of cross-shelfbreak flows it forces. Accordingly, we now examine average vertical profiles of the offshore flow of shelf water and the onshore flow of eddy and slope waters at the shelf break. We construct these profiles using the instantaneous cross-shelf dye and cross-isobath velocity fields (e.g., Fig. 6b). The velocity field is integrated in the along-isobath direction $x$ and over $\left[t_{\text {start }}, t_{\text {stop }}\right]$ to obtain a vertical profile, after restricting the domain to comprise only shelf or nonshelf (eddy and slope) water parcels.

First consider the onshore flow of eddy and slope waters. The instantaneous cross-shelfbreak velocity field for $x \gtrsim 180 \mathrm{~km}$ contains many zero crossings (Fig. 6b). A simple average will only reflect the degree to which the positive and negative velocities cancel out, obscuring our view of the flow's vertical structure. We construct a more useful average by imposing two restrictions:

1) We use only onshore velocities when integrating over eddy- and slope-water parcels. For consistency, we similarly restrict ourselves to only offshore velocities when integrating over shelf-water parcels. ${ }^{4}$

2) We restrict our along-shelf integration to $x_{\text {cen }}-1.2 L_{0} \leq x \leq x_{\text {cen }}+1.2 L_{0}$; where $x_{\text {cen }}$ is the along-shelf location of the eddy's center and $L_{0}$ is the eddy's initial radius. The decision follows from Fig. 3 where substantial offshore and onshore flows largely occur within a radius of the eddy's center, when depth averaged.

\footnotetext{
${ }^{4}$ Integrating over shelf parcels with both offshore and onshore velocities results in minor quantitative differences.
} 


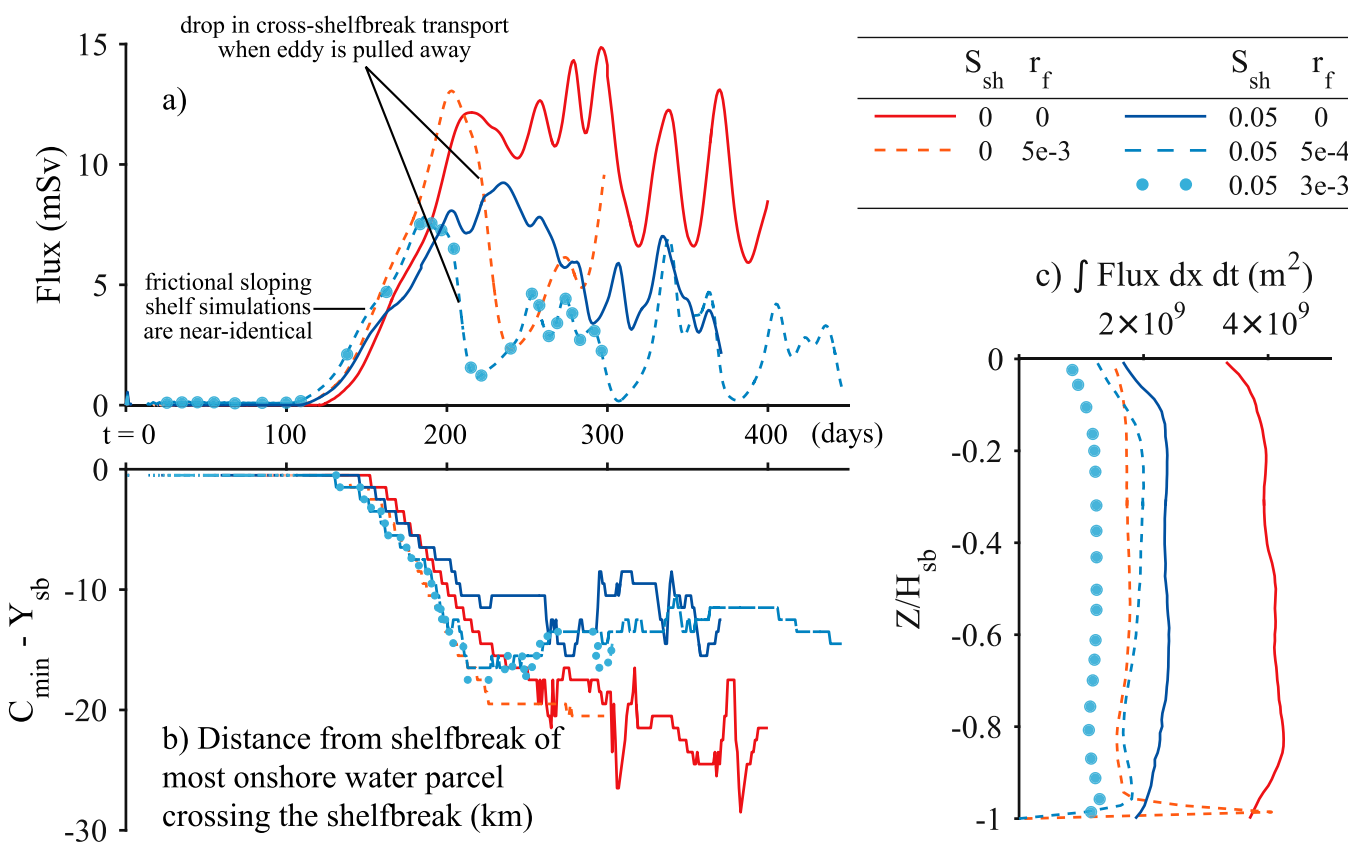

FIG. 8. Offshore flow at the shelf break is strongly influenced by a shelf slope and much less influenced by bottom friction. The reddish lines are for a flat shelf, and the bluish lines are for a sloping shelf. Dashes and filled circles indicate frictional simulations. The $S_{\mathrm{sh}}$ is the slope Burger number for the shelf, and $r_{f}$ is the linear bottom drag coefficient $\left(\mathrm{m} \mathrm{s}^{-1}\right)$. (a) Time series of offshore flux at the shelf break. The two frictional simulations with a sloping shelf have a nearly identical flux time series. (b) Lowest value of cross-shelf dye crossing the shelf break at that instant, that is, the extent to which the eddy can extract water off the shelf. Adding a slope reduces the cross-shelf scale while increasing friction with a slope does not change much. (c) Vertical structure of the $(x, t)$-integrated offshore transport.

The averaged profiles calculated from a set of inviscid simulations are presented in Fig. 9. The parameters varied include shelf slope, eddy velocity and length scales, and shelfbreak depth (Table 2). The vertical variation in each profile reflects the vertical variation in both velocity and dye fields (Fig. 6b). The average vertical structure of offshore "outflow" of shelf water and the onshore "inflow" of eddy- and slope-water across the shelf break differ for the same simulation. The eddyand slope-water inflow is always vertically sheared or baroclinic (Fig. 9b). In contrast, the export of shelf water is generally vertically uniform or barotropic with some exceptions (Fig. 9a). Strikingly, differences in vertical structure of the shelf-water outflow are seen even when the ratio of shelfbreak depth to eddy vertical scale $\lambda=H_{\mathrm{sb}} / L^{z}$ (i.e., shelf vertical scale to forcing vertical scale) is unchanged. The profiles highlighted in red in Fig. 9a are from two simulations with $\lambda=0.22 .{ }^{5}$ One is significantly more barotropic than the other. These structures and their variation will now be rationalized. We will address the flow of shelf water and nonshelf

\footnotetext{
${ }^{5}$ See ew-8381 and ew-8392 in Table 2.
}

waters separately, beginning with the supply of shelfwater parcels from the eastern boundary.

\section{b. The flow of shelf water}

\section{1) THE ALONG-SHELF SUPPLY JET}

In the following, we develop a scaling argument for the cross-shelf scale of the along-shelf supply jet. We will ignore the presence of eddy- and slope-water parcels on the shelf because these parcels occupy a minor portion of the shelf in Figs. 6a,c. In essence, we are assuming that the eddy cannot substantially penetrate onto the shelf.

The instantaneous snapshots make it clear that the along-shelf supply jet is dominantly barotropic or vertically uniform (Fig. 6d). So guided, we ignore the density field in developing a scaling for the jet's width. The dynamics of the jet is then governed by the equation for vertical relative vorticity $\zeta=v_{x}-u_{y}$ (Pedlosky 1987):

$\frac{D}{D t}(f+\zeta)=(f+\zeta) \frac{\partial w}{\partial z}+\frac{1}{\rho_{0}} \nabla \times \tau_{z}+$ tilting terms

Equation (10) can be integrated vertically between the surface and bottom to obtain the following (assuming 


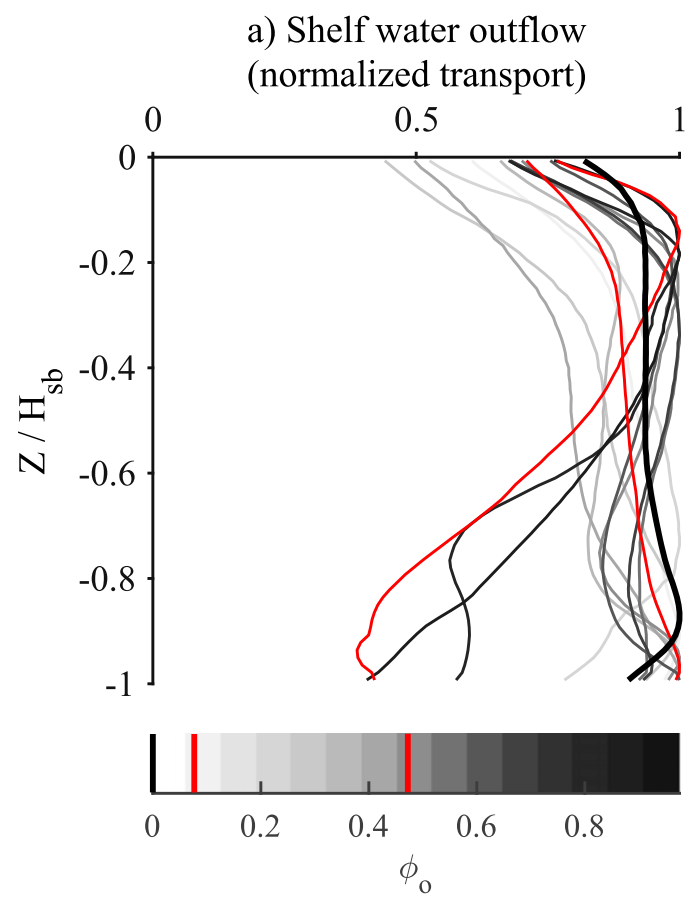

c) Supply jet on shelf (shelf water only)

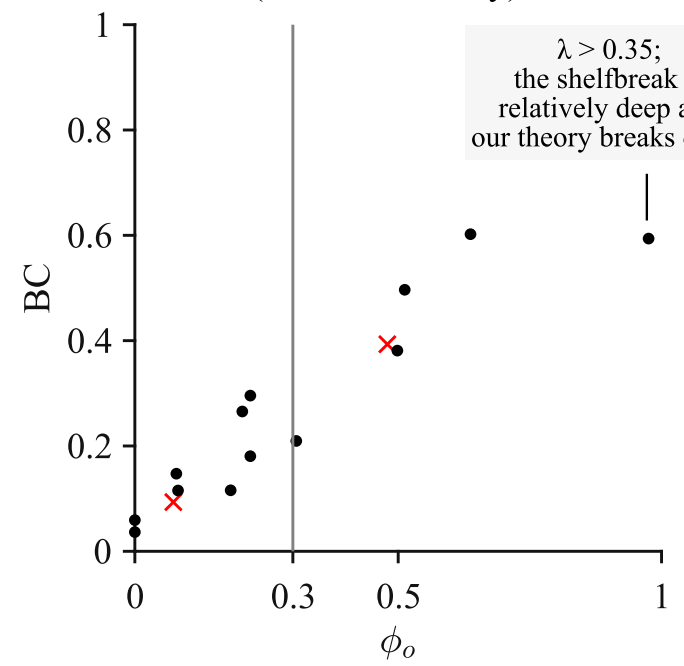

b) Eddy \& slope water inflow (normalized transport)

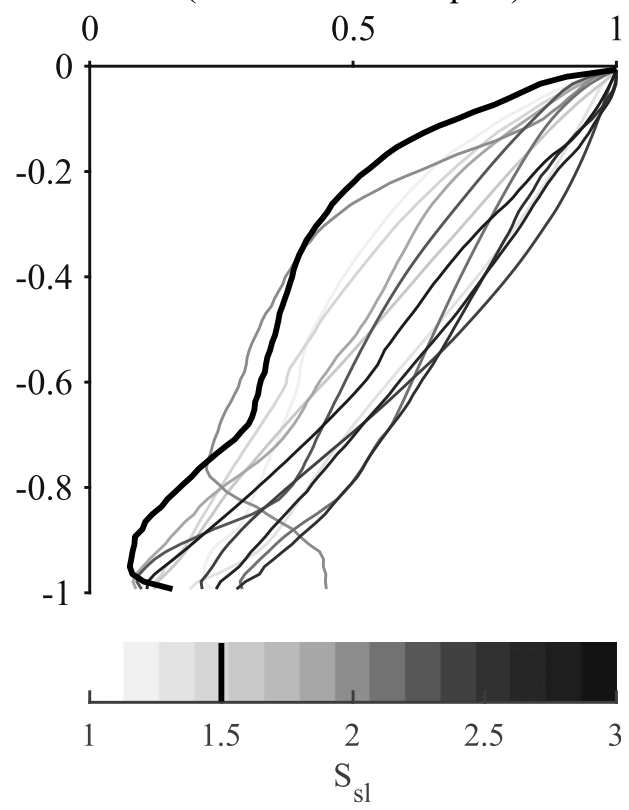

d) Outflow at shelfbreak (shelf water only)

FIG. 9. (a),(b) Vertical profiles of the time-averaged shelf-water outflow and non-shelf-water inflow at the shelf break. The time average is over $\left[t_{\text {start }}, t_{\text {stop }}\right]$. The thick black lines are for a simulation with a flat shelf, $\phi_{o}=0$ and $S_{\mathrm{sl}}=1.5$. The inflow is always baroclinic while the outflow is only sometimes baroclinic (section 5). Values are normalized such that the maximum value in each profile is 1. (c),(d) The shelf-water supply jet is more baroclinic, as measured by BC in Eq. (9), for larger values of nondimensional parameter $\phi_{o}$ (section $5 \mathrm{~b}$ ). Two simulations with $\lambda=0.22$ are highlighted in red in (a) and with a red $\times$ in (c). Despite the similarity in vertical structure of forcing, one profile is a lot more baroclinic than the other.

steady flow, ignoring tilting terms and using the bottom boundary condition $\left.w=-\alpha_{\mathrm{sh}} v^{\text {bot }}\right)$ :

$\frac{1}{H} \int_{-H}^{0} \mathbf{u} \cdot \nabla(f+\zeta) d z=\beta_{\mathrm{sh}} v^{\text {bot }}\left(1+\frac{\zeta}{f}\right)-\frac{r_{f}}{H} \zeta^{\text {bot }}$.
For inviscid simulations, the scale of the jet is set by the balance between the first two terms. We assume that both the depth-averaged along-shelf velocity and the bottom velocity $v^{\text {bot }}$ are both proportional to the eddy velocity scale $V_{0}$ (i.e., the forcing scale) and that the 
(a)

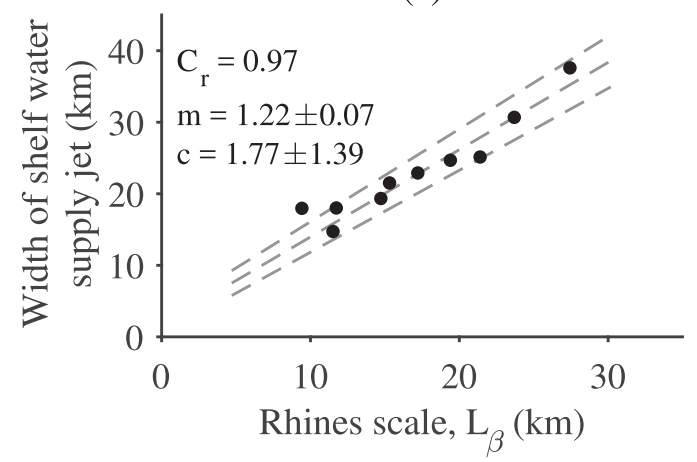

(b)

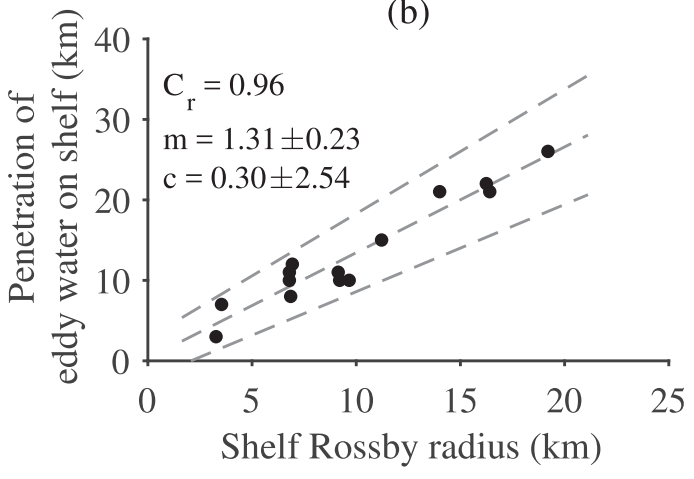

FIG. 10. Parameterizations for the cross-shelf extent from which the eddy can (a) extract water from and (b) push water onto the shelf. The dashed lines are regression lines of slope $m$ and $y$-intercept $c$ and their $95 \%$ confidence bounds. The $C_{r}$ is the correlation coefficient.

$(1+\zeta / f)$ is $O(1)$ for scaling purposes. Scaling both sides of the equation results in a horizontal length scale for the supply jet:

$$
L_{\beta}=O\left(\sqrt{\frac{V_{0}}{\beta_{\mathrm{sh}}}}\right) .
$$

We are hypothesizing that the advection of relative vorticity balances the stretching caused by shelf-water parcels moving across isobaths as they cross the shelf break. This is a turning radius argument: as the supply jet turns to cross the shelf break, its anticyclonic curvature balances the cyclonic vorticity created by nearbottom stretching. We test the length scale in Eq. (12) using simulations where $\lambda=H_{\mathrm{sb}} / L^{z}<0.35$ (Table 2). ${ }^{6}$ This is the relevant parameter range for Gulf Stream warm-core rings at the Mid-Atlantic Bight $(\lambda \approx 0.1)$.

To quantify the cross-shelf distance over which the eddy can extract shelf water, we record the lowest value of cross-shelf dye crossing the shelfbreak, $C_{\min }(t)=$ $\min _{x, z}\left[C\left(x, Y_{\mathrm{sb}}, z, t\right)\right]$ (Fig. 8b). The time series $C_{\min }(t)$ identifies the origin of the most-onshore water parcel crossing the shelf break at a given time instant. It is a measure of the cross-shelf extent of the eddy's influence. Over a flat bottom (dark red), there is no dynamical limit and the value slowly increases with time until the flow covers the entire shelf (shelf width is slightly smaller than eddy radius here). Over a sloping shelf, $C_{\min }(t)$ asymptotes out, indicating a cross-shelf limit to the eddy's influence. We fit the function $y_{1}+y_{0} \tanh \left[\left(t-t_{0}\right) / T\right]$

\footnotetext{
${ }^{6}$ When $\lambda \geq 0.35$, the shelf break is deep enough that a substantial portion of the eddy crosses on to the shelf. The eddy can then extract shelf-water parcels from a distance larger than $L_{\beta}$ from the shelf break (Cherian 2016, his Fig. 6.10). Such simulations are not examined further.
}

to $C_{\min }(t)$, with $y_{0}, y_{1}, t_{0}, T$ being constants. The width of the supply jet is estimated as $\left|y_{0}+y_{1}-Y_{\mathrm{sb}}\right|$. This diagnosed width of the along-shelf supply jet varies linearly with the length scale $L_{\beta}=\sqrt{V_{0} / \beta_{\text {sh }}}$ (Fig. 10a). On average, the eddy can extract a water parcel that starts at a distance of roughly $1.22 L_{\beta}$ away from the shelf break.

We emphasize that $1.22 L_{\beta}$ is, strictly speaking, a scale for the cross-shelf extent of the eddy's influence measured from the shelf break (Fig. 4). There are eddy- and slope-water parcels that occupy a relatively minor portion of this zone of influence (Figs. 6a,c). Section 5c(1) will address the width of the near-shelfbreak region occupied by the eddy- and slope-water parcels.

One can define a Burger number $\varphi_{o}$ that compares the supply jet length scale $L_{\beta}$ to the shelf deformation radius (Burger 1958):

$$
\varphi_{o}=\left(\frac{H_{\mathrm{sb}}}{f_{0} L_{\beta} / N}\right)^{2}=\left(\frac{N H_{\mathrm{sb}} / f_{0}}{L_{\beta}}\right)^{2} .
$$

The value of $\varphi_{o}$ indicates whether the baroclinic nature of a balanced along-isobath jet of width $L_{\beta}$ is evident over a shelf with depth $O\left(H_{\mathrm{sb}}\right)$. Over all simulations, the level of baroclinicity of the along-shelf flow BC, defined in Eq. (9), varies approximately linearly with $\varphi_{o}$ for $\varphi_{o} \lesssim 0.35$ (Fig. 9c). As $\varphi_{o}$ increases, the shelf-water supply jet appears increasingly sheared in the vertical because the shelf is now effectively deeper.

\section{2) THE CROSS-SHELFBREAK OUTFLOW OF SHELF WATER}

The supply jet flow turns and crosses isobaths once it nears the eddy. The kinematic bottom boundary condition $w=\mathbf{u} \cdot \nabla H$ requires that near-bottom water parcels in a cross-isobath flow move vertically, advect the background density field, and thereby create 
near-bottom density anomalies. We now examine whether these density anomalies affect the vertical structure of the supply jet when it turns to cross the shelf break. At the bottom, the inviscid density in Eq. (5) can be written in terms of buoyancy anomaly $b=-g \rho / \rho_{0}$ :

$$
\frac{D b}{D t}+w N^{2}=0, \quad z=-H(y) .
$$

Assuming a steady outflow and applying the bottom boundary condition $w=\mathbf{u} \cdot \nabla H$ yields

$$
u b_{x}+v b_{y}=-(\mathbf{u} \cdot \nabla H) N^{2}, \quad z=-H(y) .
$$

Through thermal wind balance, the density anomaly can be expressed as geostrophic, vertically sheared, anomalous along- and cross-isobath velocity fields, ${ }^{7}$ given by $\left(u^{g}, v^{g}\right), f_{0} v_{z}^{g}=b_{x}$, and $-f_{0} u_{z}^{g}=b_{y}$. Following Brink (1998), we write the LHS of Eq. (15) in vector form using $\mathbf{k}$ to represent the normal vector in the vertical direction, $\mathbf{u}=(u, v)$ and $\mathbf{u}_{z}^{g}=\left(u_{z}^{g}, v_{z}^{g}\right)$ :

$$
f_{0} \mathbf{k} \cdot \mathbf{u} \times \mathbf{u}_{z}^{g}=-(\mathbf{u} \cdot \nabla H) N^{2}, \quad z=-H(y) ;
$$

then we rewrite the above as

$$
|\mathbf{u}|\left|\mathbf{u}_{z}^{g}\right| \sin \theta^{z}=-\frac{N^{2}}{f_{0}}|\mathbf{u}||\nabla H| \cos \theta^{H}, \quad z=-H(y) .
$$

The $\theta^{z}, \theta^{H}$ are the angles between the velocity vector $\mathbf{u}$ and the geostrophic velocity shear vector $\mathbf{u}_{z}^{g}$ and between the velocity vector $\mathbf{u}$ and the topographic gradient vector $\nabla H$. For nonzero cross-isobath velocity (RHS $\neq 0$ ), the LHS of Eq. (17) implies that 1) there must be near-bottom geostrophic shear $\left(\left|\mathbf{u}_{z}^{g}\right| \neq 0\right)$, and 2) this shear must necessarily be oriented at an angle to the velocity vector so that $\sin \theta^{H} \neq 0$ (i.e., acting to turn the jet). We can now judge the effectiveness of the nearbottom geostrophic shear $\left|\mathbf{u}_{z}^{g}\right|$ throughout the water column by scaling Eq. (17). Using our previous assumption that the along-shelf supply jet velocity $|\mathbf{u}|$ scales like the eddy velocity scale $V_{0}$,

$$
\begin{aligned}
\frac{\left|\mathbf{u}_{z}^{g}\right| H_{\mathrm{sb}}}{|\mathbf{u}|} \sim \frac{\alpha_{\mathrm{sh}} N^{2} H_{\mathrm{sb}}}{f_{0}|\mathbf{u}|} \sim O\left(\frac{\alpha_{\mathrm{sh}} N^{2} H_{\mathrm{sb}}}{f_{0} V_{0}}\right) & =O\left(\frac{H_{\mathrm{sb}}^{2}}{f^{2} L_{\beta}^{2} / N^{2}}\right) \\
& =O\left(\varphi_{o}\right) .
\end{aligned}
$$

The modification of vertical shear by these near-bottom anomalies is on the same order as the shear that would be present in a balanced jet of scale $L_{\beta}$, if the shelf is deep enough. Following (18), $\varphi_{o}$ should be an effective predictor of the shear of the cross-shelfbreak flow, just

\footnotetext{
${ }^{7}$ The superscript $g$ is for geostrophy.
}

as for the along-shelf supply jet. We check this prediction by calculating $\mathrm{BC}$ using the cross-shelf velocity $v$ at the shelf break and testing its variation against $\varphi_{o}$ (Fig. 9d). Again, there is an approximately linear dependence with $\varphi_{o}$. The offshore outflow of shelf water is increasingly vertically sheared as $\varphi_{o}$ increases, as for the supply jet. Figure $9 \mathrm{~d}$ presents a more nuanced, and more accurate, picture than the average profiles in Fig. 9a. The averaged profiles are colored such that darker gray lines correspond to larger values of $\varphi_{o}{ }^{8}$ What appears to be a sharp change in vertical structure of the offshore flow based on parameter $\varphi_{o}$ in Fig. 9a is actually a gradual linear increase of vertical shear with $\varphi_{o}$ in Fig. 9d. The parameter BC in Fig. 9d is a more accurate characterization of the instantaneous state of the flow, whereas Fig. 9a averages over the spatially complex dye field at the shelf break (Fig. 6b). Regardless, both diagnostics indicate that the eddy-forced offshore flow samples the entire water column over the outer shelf (BC $<1$ throughout).

When disregarding water-mass type, the along-shelf scale of offshore flow at the shelfbreak is an eddy radius (Fig. 3). Attempts to parameterize the along-shelf scale of the offshore flow of shelf water at the shelf break (i.e., the streamer) were unsuccessful. Doing so could possibly require a more detailed examination of baroclinic processes at the eddy-shelf-water front.

\section{c. The flow of eddy and slope waters}

\section{1) THE CROSS-SHELFBREAK INFLOW OF EDDY AND SLOPE WATERS}

The vertical structure of the eddy-water inflow onto the shelf is always baroclinic (Fig. 9b). The densityanomaly-based reasoning of the previous section does not apply in this case because the appropriate bottom slope, that of the continental slope, is quite steep $\left(S_{\mathrm{sl}} \geq 1\right.$; Table 2). The kinematic bottom boundary condition imposes $w=\mathbf{u} \cdot \nabla H=\alpha v$ at the bottom, where $v$ is crossisobath velocity and $\alpha$ is the bottom slope. For infinite slope $\alpha$ (i.e., a vertical wall), the appropriate boundary condition is $v=0$. As bottom slope $\alpha$ increases, there must be a transition from a regime where the appropriate boundary condition is $w=\alpha v$ to one where $v=0$ (i.e., as $\alpha \rightarrow \infty, v \rightarrow 0$ ), so that $w$ is bounded. The upper bound on $w$ is set by the continuity equation that imposes $w \leq O$ $(V D / L)$, where $V$ is the cross-isobath velocity scale and $D, L$ are appropriate vertical and horizontal scales.

Scaling $w$ from the bottom boundary condition as $w \sim$ $O\left(\alpha_{\mathrm{sl}} V\right)$ and comparing it to the upper bound from the

\footnotetext{
${ }^{8}$ The red lines illustrate that $\varphi_{o}$ rather than $\lambda$ controls the vertical structure of the offshore transport (section $5 \mathrm{a}$ ).
} 
continuity equation $O(V D / L)$ yields (assuming that $D / L \sim f / N)$

$$
\begin{aligned}
w & \sim O\left(\alpha_{\mathrm{sl}} V\right) \lesssim O(V D / L), \quad \text { and } \\
O\left(\alpha_{\mathrm{sl}} V\right) & \lessgtr O(V f / N) \Rightarrow S_{\mathrm{sl}} \lesssim O(1) .
\end{aligned}
$$

When $S_{\mathrm{sl}} \lessgtr O(1)$, the slope is gentle and the crossisobath flow is deflected either up- or downslope (i.e., $v_{y} \approx-w_{z}$ ) and the flow is approximately twodimensional in the $y-z$ plane. When $S_{\mathrm{sl}}>O(1)$, the slope is steep and acts like a vertical wall that deflects the nearbottom cross-isobath flow in the along-isobath direction. Now the flow is approximately two-dimensional in the horizontal $x-y$ plane and $u_{x} \approx-v_{y}$.

Over the shelf where $S_{\mathrm{sh}} \leq 0.2$, Eq. (19) is satisfied and the sloping shelf forces vertical motion affecting the supply jet as described in the previous section. For the continental slope, however, $S_{\mathrm{sl}} \geq 1$ and the slope is expected to force $v \approx 0$ as in Fig. 11c. The thick green contour is for a tenth of the peak surface cross-isobath velocity. At the surface, the eddy forces a small but nonzero crossisobath velocity $v$. Below shelfbreak depth, the slope forces $v \approx 0$ and creates a stagnation line over the upper slope near the shelf break (Fig. 11b), pinching the cross-shelf velocity contours in Fig. 11c. Near the surface there is still small but nonzero cross-shelfbreak flow forced by the eddy, resulting in strong vertical shear between the surface and shelfbreak depth (Fig. 9b).

\section{2) ALONG-SHELF FLOW OF EDDY AND SLOPE WATERS (THE LEAKAGE)}

The baroclinic inflow of eddy and slope waters rotates to follow isobaths after it crosses the shelf break. Being strongly sheared at the shelf break (Figs. 6c,d), we hypothesize that the cross-isobath scale of the balanced along-shelf flow should scale with the shelf deformation radius $N H_{\mathrm{sb}} / f$. This hypothesis is tested using the depthand time-averaged cross-shelf dye field $C_{\text {mean }}(y)=$ mean $_{z, t}\left[C\left(x_{0}, y, z, t\right)\right]$ at a location $x=x_{0}$ near the eastern sponge. The time average is calculated over $\left[t_{\text {start }}, t_{\text {stop }}\right]$. The width of the eddy- and slope-water leakage on the shelf is defined as the $y$ location where $C_{\text {mean }}(y)=Y_{\mathrm{sb}}$, this being the time- and depth-averaged location of the dye front between shelf and nonshelf waters. The instantaneous dye front is the thick blue contour in Figs. $6 \mathrm{c}, \mathrm{d}$. The diagnosed location of the dye front scales linearly with the shelf deformation radius in Fig. 10b, confirming our hypothesis.

\section{The cross-shelfbreak flux of shelf water}

The addition of a sloping shelf reduces the crossshelfbreak offshore transport of shelf water as compared
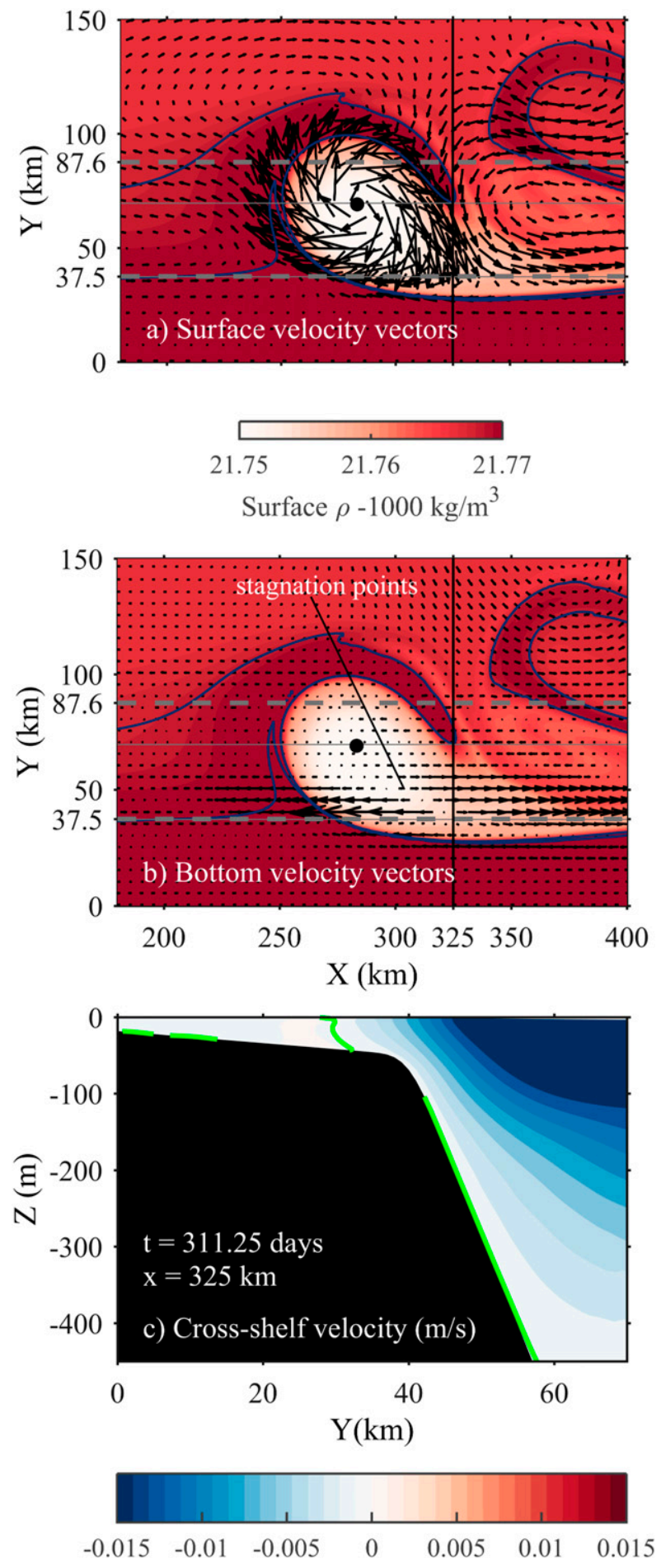

FIG. 11. Snapshots for a simulation with $\phi_{o}=0.35$. (a),(b) Surface density in color with surface and bottom velocity vectors in (a) and (b), respectively. (c) The vertical structure of cross-shelf velocity where eddy water moves onto the shelf. The thick green contour is $v=10^{-4} \mathrm{~m} \mathrm{~s}^{-1}$.

to the corresponding flat shelf simulation (section $4 \mathrm{~d}$ ). The effect of a shelf slope is to reduce the volume of shelf water that can be affected by the eddy-the supply 
jet's cross-shelf scale is reduced to $1.22 L_{\beta}$ (section $5 b$ ). In contrast, the supply jet's cross-shelf scale over a flat shelf is the forcing scale (i.e., an eddy radius), unless the shelf is narrower. For example, in Fig. 7 the shelf width is smaller than the eddy radius and the supply jet is visible over the entire shelf. We hypothesize that the reduction in the supply jet's cross-shelf scale is the cause of the reduced offshore transport of shelf water and will now test this assertion.

We make five assumptions:

1) First, for simplicity, assume that the eddy's velocity field decays as an exponential function over the shelf in the cross-shelf direction.

2) Over a flat shelf, the decay scale for the exponential is the eddy's horizontal scale $L_{0}$. Over a sloping shelf, we assume the cross-shelf decay scale to be $L_{s} \equiv$ $1.22 L_{\beta}$ instead of the eddy radius $L_{0}$ (Fig. 10a).

3) We assume that the eddy's vertical scale is large compared to shelfbreak depth $H_{\mathrm{sb}}$, so that the forcing velocity field is barotropic over the shelf.

4) We ignore the near-shelfbreak presence of eddy and slope waters.

5) Finally, we write the along-shelf velocity magnitude of shelf water in the supply jet as $c_{1} V_{0}$, where $V_{0}$ is the eddy velocity scale and $c_{1}$ is an $O(1)$ constant.

The supply jet transport $Q_{f}$ over a flat shelf of width $L_{\mathrm{sh}}$ is then the integral of the velocity field $\left(y \equiv y-Y_{\mathrm{sb}}\right.$ so that $y=0$ at the shelf break here):

$$
\begin{aligned}
& Q_{f}=c_{1} \int_{-L_{\mathrm{sh}}}^{0} \int_{-H_{\mathrm{sb}}}^{0} V_{0} e^{-|y| L_{0}} d z d y, \quad \text { and } \\
& Q_{f}=-c_{1} V_{0} H_{\mathrm{sb}} L_{0}\left[1-e^{-\left(L_{\mathrm{sh}} / L_{0}\right)}\right] .
\end{aligned}
$$

Using $L_{s} \equiv 1.22 L_{\beta}$ instead of eddy radius $L_{0}$ as the crossshelf decay scale for the velocity field over a sloping shelf, we analogously write

$$
\begin{aligned}
Q_{\alpha}= & c_{1} \int_{-L_{\mathrm{sh}}}^{0} \int_{-h(y)}^{0} V_{0} e^{-|y| L_{s}} d z d y, \text { and } \\
Q_{\alpha}= & -c_{1} V_{0} H_{\mathrm{sb}} L_{s} \\
& \times\left[\left(1-\frac{\alpha_{\mathrm{sh}} L_{s}}{H_{\mathrm{sb}}}\right)\left(1-e^{-L_{\mathrm{sh}} / L_{s}}\right)-\frac{\alpha_{\mathrm{sh}} L_{\mathrm{sh}}}{H_{\mathrm{sb}}} e^{-L_{\mathrm{sh}} / L_{s}}\right] .
\end{aligned}
$$

We hypothesize that the effect of a sloping shelf is fully encapsulated in the "slope factor," given by $\sigma=Q_{\alpha} / Q_{f}$, $\alpha_{\mathrm{sh}} \neq 0$, such that $\sigma=1$ when $\alpha_{\mathrm{sh}}=0$. We test this hypothesis by using four sets of simulations; ${ }^{9}$ each set is

\footnotetext{
${ }^{9}$ The sets are $\{8380,8381,8383,8384,8385\} ;\{34,8341\} ;\{8350-2$, $8351-2,8352-2\}$, and $\{8040,8041,8042\}$ in Table 2.
}

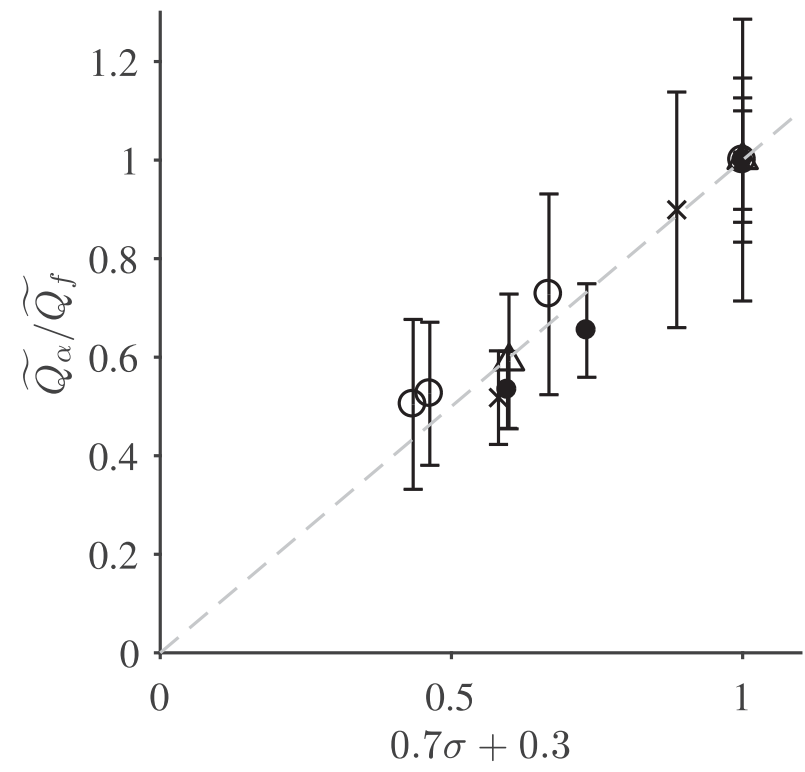

FIG. 12. Increasing shelf slope reduces the cross-shelfbreak offshore flux of shelf water. The magnitude of decrease is largely explained by the change in shelf volume that the eddy can extract water from (section 6). Markers indicate different sets of simulations. Within each set (same marker), the simulations differ only in shelf parameters; the eddy remains the same. The different sets differ in choice of eddy parameters and $f_{0}, N^{2}$. The diagonal dashed line is the $45^{\circ}$ line.

marked using a different marker in Fig. 12. Within each set of simulations (same markers), only the shelf slope is changed. Between different sets (different markers), both eddy and shelf properties are changed. We normalize the "true" average flux estimated for simulations with a sloping shelf $\widetilde{Q_{\alpha}}$ by the "true" average estimated for the corresponding flat bottom run $\widetilde{Q_{f}}$. The ratio $\widetilde{Q_{\alpha}} / \widetilde{Q_{f}}$ is well modeled by the straight line (Fig. 12):

$$
\frac{\widetilde{Q_{\alpha}}}{\widetilde{Q_{f}}}=0.7 \sigma+0.3 .
$$

A sloping shelf reduces the cross-shelf scale of the eddy's influence and, in doing so, reduces the offshore transport of shelf water.

Cherian and Brink (2016, sections 8 and 9d) regressed the true value of average offshore transport $\widetilde{Q_{\alpha}}$ for a sloping shelf against $Q_{f}$ (prediction for flat shelf, their $Q$ ) to obtain an offshore flux estimate for sloping shelves. Having proposed an explanation for how a sloping shelf influences offshore transport, we can easily update that recipe to use a decay scale of $1.22 L_{\beta}$ instead of the eddy radius $L_{0}$ when the shelf is sloping and obtain a better estimate of eddy-forced offshore flux of shelf water. Regressing the true value of average offshore transport $\widetilde{Q_{\alpha}}$ against our updated prediction $Q_{\alpha}$ yields a regression 
slope of 0.2 and a correlation coefficient of 0.95 . To summarize, in the case of a sloping shelf we calculate $Q_{\alpha}$ using Eq. (24) after setting $c_{1}=0.2$ to obtain an estimate of the eddy-forced offshore transport of shelf water.

\section{The effect of bottom friction}

With the addition of bottom friction, the picture remains qualitatively similar. The presence of friction is more important than its magnitude, as is now described. We use a set of simulations where only linear bottom friction magnitude $r_{f}$ is varied. Other parameters are set so that they match (nondimensionally) the interaction of Gulf Stream warm-core rings with the Mid-Atlantic Bight. Compare a simulation with no bottom stress (Figs. 13a,b) with one where the linear bottom friction coefficient $r_{f}=3 \times 10^{-3} \mathrm{~m} \mathrm{~s}^{-1}, f_{0}=5 \times 10^{-5} \mathrm{~s}^{-1}$, $H_{\mathrm{sb}}=50 \mathrm{~m}$, and Ekman number Ek $=r_{f}\left(f_{0} H_{\mathrm{sb}}\right)=1.2$ (Figs. 13c,d). Representative values for the real-world coastal ocean are $r_{f}=5 \times 10^{-4} \mathrm{~m} \mathrm{~s}^{-1}$ and Ek $=0.05$ for the Mid-Atlantic Bight $\left(f_{0}=10^{-4} \mathrm{~s}^{-1}\right.$ and $\left.H_{\mathrm{sb}}=100 \mathrm{~m}\right)$. Despite the large value, the flow evolution on the shelf is relatively unaffected (Fig. 13a). All differences in the frictional simulation can be traced to the spinup of a stronger secondary cyclone that pulls the eddy away from the shelf break $(x \approx 250-300 \mathrm{~km}$ in Figs. $13 \mathrm{c}$,d; Cherian and Brink 2016). The increased vorticity is generated in the bottom boundary layer over the slope. Both simulations are nearly identical until the eddy is pulled away, after which the forcing at the shelf break and over the shelf drops. There is a corresponding drop in cross-shelfbreak flux magnitude (Fig. 8a) and the along-shelf flow over the shelf weakens (Fig. 13d). This drop in flux magnitude at $t \approx 200$ days is similar to that seen for a frictional flat shelf (Fig. 8a). When the shelf is sloping, frictional simulations attain nearly the same maximum flux as the corresponding inviscid simulation (cf. blue lines in Fig. 8a). The time-averaged flux magnitude is lower because the eddy moves away from the shelf break frequently. Increasing $r_{f}$ from $5 \times 10^{-4} \mathrm{~m} \mathrm{~s}^{-1}$ by a factor of 6 to $3 \times 10^{-3} \mathrm{~m} \mathrm{~s}^{-1}$ does not change the flux magnitude time series; this insensitivity is surprising.

The cross-shelf extent of the supply jet is also insensitive to bottom friction magnitude. For this section, we define the jet's cross-shelf extent as the cross-shelf distance over which the instantaneous along-shelf depth-averaged velocity drops to $30 \%$ of its value at the shelf break. The scale is estimated near the eastern boundary, downstream from the eddy. Time series of this quantity for simulations with $r_{f}$ varying from 0 to $3 \times 10^{-3} \mathrm{~m} \mathrm{~s}^{-1}$ are shown in Fig. 13e. The reduction in cross-isobath scale at $t \approx 23$ days occurs when the eddy is pulled away from the shelf break, reducing the forcing magnitude. Then the only significant shelf-water velocities are near the leakage at the shelf break, where the along-shelf flow balances the density gradient between the ambient shelf water and the eddy water at the shelfedge (Fig. 13d). These conditions persist until the eddy loops back to the shelf break at $t \approx 300-320$ days, at which point there is significant eddy forcing over the shelf and $\mathrm{BC}(t)$ drops to approximately 0.1 , indicating the presence of a barotropic supply jet. In total, varying nonzero bottom friction has little effect on the maximum cross-isobath extent of the supply jet despite the large variation in $r_{f}$ values used. This conclusion is also supported by $C_{\min }(t)$ in Fig. 8b.

Bottom friction could affect the scales of the alongisobath supply jet in four ways:

1) Buoyancy arrest might limit the jet's cross-isobath extent (Brink 2012).

2) If large enough, friction could modify the change the scale of the supply jet by changing the RHS of Eq. (11).

3) Arrested topographic wave physics could widen the jet downstream of the eddy (Csanady 1978).

4) Stratified spindown might make the jet more baroclinic (Holton 1965).

Buoyancy arrest is easily ruled out: for barotropic flows, the expressions of Brink (2012) predict an along-isobath adjustment scale of at least a $1000 \mathrm{~km}$ for buoyancy arrest to influence the cross-isobath scale of the supply jet. Next, section $5 b$ argues that the cross-shelf scale of the supply jet is set by a relative vorticity constraint operating where the eddy forces the jet to turn offshore. We compare the stretching and frictional terms in Eq. (11), setting $\alpha_{\mathrm{sh}}=10^{-3}, L_{\beta}=12 \mathrm{~km}$, and $H_{\mathrm{sb}}=50 \mathrm{~m}$ :

$$
\begin{gathered}
\frac{r_{f} u_{y}^{\mathrm{bot}}}{f \alpha_{\mathrm{sh}} \mathrm{v}^{\mathrm{bot}}} \sim O\left(\frac{r_{f}}{f_{0} \alpha_{\mathrm{sh}} L_{\beta}} \frac{u^{\mathrm{bot}}}{v^{\mathrm{bot}}}\right), \quad \text { and } \\
\sim \frac{\mathrm{Ek}}{O\left(10^{-3} \times 12 \times 10^{3} / 50\right)} \times O(u / v) \approx 4 \mathrm{Ek} \times O\left(u^{\left.\mathrm{bot} / v^{\mathrm{bot}}\right) .}\right.
\end{gathered}
$$

Where the jet turns offshore near the eddy, $u^{\text {bot }} \sim v^{\text {bot }}$ and friction is as important as the stretching term when $\mathrm{Ek} \geq 0.25$. By generating anticyclonic vorticity and thence reducing the RHS, it should widen the supply jet. Instead, the supply jet's cross-isobath scale is relatively unmodified from its inviscid value for $\mathrm{Ek}=0.02,0.04$, $0.2,1.2(t<230$ days in Fig. 13e). We have not been able to rationalize this insensitivity but note that the frictional term is much smaller than the stretching term in Eq. (11) for the realistic value $\mathrm{Ek} \sim 0.05$ and $L_{\beta}$ is expected to be a good estimate of the supply jet's crossshelf scale. In some contexts the insensitivity to large 



FIG. 13. The influence of bottom friction. Snapshots of SSH (both color and contours) and surface velocity vectors for two simulations, one with (a),(b) $r_{f}=0$ and the other with (c),(d) $r_{f}=3 \times 10^{-3} \mathrm{~m} \mathrm{~s}^{-1}$. Negative SSH contours are dashed. The vectors are for illustration and not comparable between panels. (e) Time series of cross-shelf scale of along-shelf flow. (f) The $\mathrm{BC}(t)$ for the two simulations. Nonzero bottom friction coefficient spins up a strong secondary cyclone that pulls the eddy away from the shelf break at $t=230$ days, causing both a decrease in crossshelf scale of the along-shelf flow and an increase in $\mathrm{BC}(t)$. 
values of bottom friction indicates that stratified spindown has reduced near-bottom velocities so that the frictional term is less important (e.g., Brink 2017). However, we now show that stratified spindown too is ineffective and that the supply jet is nearly barotropic.

At first, it appears that bottom friction does make the along-shelf supply jet more baroclinic, as measured by the time series BC(t) (Fig. 13f). The time series is obtained using Eq. (9) at each time step; that is, we do not compute the median over $\left[t_{\text {start }}, t_{\text {stop }}\right]$ in this case. As with the reduction in cross-isobath scale, the localized alongshelf baroclinic flow of the leakage is responsible for the much larger value of $\mathrm{BC}(t)$ at $t=230$ days. Prior to this time, the evolution of $\mathrm{BC}(t)$ is comparable to that of the inviscid simulation. When there is substantial eddy forcing over the shelf, frictional and inviscid simulations are near identical. The explanation is that stratified spindown is expected to act over a vertical scale $\sim O(f L / N)$. For this particular simulation, the jet is barotropic with approximate cross-isobath scale $L_{\beta}=\sqrt{V_{0} / \beta_{\mathrm{sh}}}$. Its vertical scale $f L_{\beta} / N \approx 4 H_{\mathrm{sb}}$ (i.e., $\varphi_{o}=0.06$ ), ${ }^{10}$ so the spindown should affect the water column equally at all depths above the bottom Ekman layer. The BC, being calculated over the shelf above the bottom Ekman layer, is thus unaffected by the spindown (Fig. 13f). Vertical profiles of the outflow at the shelf break are also barotropic with a shallow Ekman layer near the bottom (Fig. 8c). In addition, the bottom stress over the shelf does increase with increasing bottom friction parameter $r_{f}$ indicating that spindown is not occurring.

One can also rule out arrested topographic wave physics (Csanady 1978). For a linear flow, the balance in Eq. (11) reduces to one between near-bottom vortex stretching and frictional spindown:

$$
0=\beta_{\mathrm{sh}} v^{\text {bot }}-\frac{r_{f}}{H} \zeta^{\text {bot }} .
$$

Csanady (1978) shows this equation to be diffusive: the along-shelf flow spreads (diffuses) in the cross-shore direction, becoming wider or narrower as it moves in the coastal-trapped wave direction. The flow must cross isobaths and generate stretching or compression to compensate for frictional removal of vorticity. ${ }^{11}$ If such a balance were possible, the along-shelf supply jet in Figs. 13c,d would widen as it approaches the eastern boundary, changing the volume of shelf water affected by

\footnotetext{
${ }^{10}$ This is just as for Gulf-Stream warm-core rings at the MidAtlantic Bight.

${ }^{11}$ Csanady's version is recovered for a barotropic flow with SSH $\eta(x, y, t)$ by setting $v^{\text {bot }}=g / f \eta_{x}, \zeta^{\text {bot }}=g \nabla^{2} \eta$. and making the long wave assumption- $L_{x} \gg L_{y}, v^{\text {bot }} / u^{\text {bot }} \sim L_{y} / L_{x} \ll 1$ - so that $\zeta^{\text {bot }} \approx g \eta_{y y}$.
}

the eddy. Near the eastern boundary, the along-shelf scale of the supply jet is much larger than its cross-shore scale (Fig. 13c) and accordingly cross sections show that $u^{\text {bot }} \sim O(100) v^{\text {bot }}$. Equation (26) then implies that these scales are such that the flow cannot generate enough vorticity through near-bottom stretching to compensate for frictional spindown. The steady-state arrested topographic wave balance in Eq. (28) cannot be realized, and the supply jet's width is unchanged as it propagates downstream.

In summary, all differences in the frictional simulations can be traced to the spinup of a stronger secondary cyclone when the eddy impacts the continental slope. The cross-shelf scale of the supply jet is insensitive to the magnitude of friction. A dynamical explanation for this behavior remains elusive. Bottom friction on the continental slope has a greater effect on the eddy-shelf interaction than bottom friction on the shelf.

\section{Discussion}

\section{a. Summary}

We used a suite of continuously stratified primitive equation simulations to study the interaction of anticyclonic eddies with continental shelf-slope topography. Cherian and Brink (2016) described the fate of the exported shelf water and proposed a scaling for the magnitude of offshore flux of shelf water for a flat shelf. Here, we studied the shelf flows forced by these eddies and derived scalings for their horizontal and vertical structure (summarized in Fig. 4). These scalings allowed us to extend the offshore flux parameterization of Cherian and Brink (2016) to account for a sloping shelf. The broad conclusions presented in Cherian and Brink (2016) regarding volume budgets for the Mid-Atlantic Bight shelf are unchanged.

The shelf water exported by the eddy never returns to the shelf: it is trapped in the stacked cyclones described in Cherian and Brink (2016) (also, Fig. 2). The lost shelf water is compensated by an along-shelf jet that supplies shelf water from downstream of the eddy, in the coastaltrapped or Kelvin wave sense, as in the linear simulations of Chapman and Brink (1987) and as speculated by Lee and Brink (2010). This along-shelf supply jet is barotropic and its cross-shelf scale is limited: distance $1.22 L_{\beta}=1.22 \sqrt{V_{0} / \beta_{\text {sh }}}$ from the shelf break on average (Figs. 4, 7, and 10). The $L_{\beta}$ can be interpreted as either a turning radius, an inertial length scale, or a stationary topographic Rossby wavelength scale (Pedlosky 1987). For the presented simulations, the supply jet is generally barotropic and its vertical shear depends on parameter $\varphi_{o}$, a Burger number comparing the jet's cross-shelf 
scale $L_{\beta}$ to the shelf Rossby radius. On nearing the eddy, the along-shelf supply jet turns offshore. The nearbottom density anomalies created when the jet turns, and crosses isobaths, are generally not strong enough to appreciably change the vertical structure of the jet (Fig. 9).

The eddy also transports eddy and slope waters on to the shelf, compensating for the lost shelf-water volume. These waters form a gravity currentlike flow moving downstream in the Kelvin-wave direction, whose average cross-shelf extent is a shelf Rossby radius from the shelf break (also see Shi and Nof 1993; Zhang and Gawarkiewicz 2015). The baroclinic nature of the current is apparent in cross-shelf sections of the flow field (Figs. 6c,d). Most notably, the vertical structure of the shelf-water outflow and eddy-water inflow can be different. At the shelf edge, the offshore flow of shelf water is generally barotropic (vertically uniform), while the onshore flow of eddy and slope waters is generally baroclinic (vertically sheared; Fig. 9). Qualitatively, linear bottom friction has little effect on the shelf flow field. Its biggest effect is to strengthen the secondary cyclone that pulls the eddy away from the shelf break, thereby reducing the strength of the eddy forcing on average. The above results are subject to the same caveat as Cherian and Brink (2016); that is, the planetary $\beta$ plane continuously forces the eddy into the slope. Without competing influences from background flows and other mesoscale eddies, the eddy's edge always reaches the shelf break, remains there for a large amount of time, and strongly affects the shelf. Our scalings for length scales and crossshelf fluxes are thus an upper bound. With this in mind, we now discuss implications for the Mid-Atlantic Bight.

\section{b. Implications and observations: The Mid-Atlantic Bight shelf}

For the Mid-Atlantic Bight shelf, $\alpha_{\mathrm{sh}} \approx 10^{-3} \mathrm{~mm}^{-1}$, annual mean $N \approx 10^{-2} \mathrm{~s}^{-1}$ (Zhang et al. 2011), $f_{0}=$ $10^{-4} \mathrm{~s}^{-1}$, and $H_{\mathrm{sb}} \approx 100 \mathrm{~m}$. A typical Gulf Stream warmcore ring velocity is $O(1.5) \mathrm{m} \mathrm{s}^{-1}$. Using these values, the Burger number is given by

$$
\varphi_{o}=\frac{S_{\mathrm{sh}} N H_{\mathrm{sb}}}{V_{0}}=\frac{0.1 \times 10^{-2} \times 100}{1.5} \approx 0.06 .
$$

The estimated $\varphi_{o}$ suggests that shelf-water outflow should be barotropic above the bottom boundary layer and that the along-shelf supply jet width should scale like $1.22 L_{\beta}$. With the above choices, warm-core rings should be able to extract shelf-water parcels that are an approximate distance of $1.22 L_{\beta} \approx 55 \mathrm{~km}$ from the shelf break. The eddy-water inflow is expected to penetrate about $1.33 N H_{\mathrm{sb}} / f_{0} \approx 14 \mathrm{~km}$ inshore. We remind the reader that these length scale estimates are an (average) upper bound. Bottom friction should not affect these estimates, which are based on an inviscid theory (section 7).

Drifter observations reported in Brink et al. (2003) indicate that shelf water between the surface and at least 40-m depth ${ }^{12}$ are exported by warm-core rings at the shelf break off George's Bank (shelfbreak depth $100 \mathrm{~m}$; Fig. 1). The most onshore drifter that crossed the shelf break started at the $60 \mathrm{~m}$ isobath, roughly $50 \mathrm{~km}$ inshore of the shelf break, consistent with our prediction of $60 \mathrm{~km}$. Lee and Brink (2010) too observed that the ring affected the entire shelf-water column from surface to bottom (less than $100 \mathrm{~m}$ deep here). Their observations show the warm eddy-water intrusion (leakage) extends nearly to the shelf bottom in some places. The associated velocity field was surface intensified "with little or no flow near the bottom." The latter is again as expected since $S_{\mathrm{sl}}>1$ for the continental slope off the MidAtlantic Bight [Fig. 9b; and section 5c(2)]. Ring water is present roughly $25-40 \mathrm{~km}$ inshore of the $100-\mathrm{m}$ isobath, much larger than our estimate of $14 \mathrm{~km}$. Sections presented in Lee and Brink (2010) do show the enhanced penetration to be associated with the eddy-water intrusion wrapping up into a small eddy approximately $20 \mathrm{~km}$ wide. Such processes are not accounted for in our prediction of the average cross-shelf scale. More recently, Zhang and Gawarkiewicz (2015) observed warm-core ring water intruding approximately $20 \mathrm{~km}$ inshore of the $100-\mathrm{m}$ isobath, better agreement with our 14-km estimate. Glider observations in Zhang and Gawarkiewicz (2015) too show ring density water extending nearly to the bottom just as in Fig. $6 \mathrm{~d}$ and Lee and Brink (2010). These observations are generally consistent with the predictions presented previously despite the absence of a shelfbreak front in our simulations.

The updated flux parameterization that accounts for a sloping shelf yields the same shelf-water flux estimate for the Mid-Atlantic Bight presented in Cherian and Brink (2016, section 9d), namely, 0.3-0.7 Sv (1 Sv $\equiv$ $\left.10^{6} \mathrm{~m}^{3} \mathrm{~s}^{-1}\right)$. Since the conclusions are unchanged, the reader is referred there for a discussion of this flux estimate in the context of existing budgets for the MidAtlantic Bight shelf.

\section{c. Limitations and future extensions}

As in Cherian and Brink (2016), there are drawbacks to the approach used. First, in the absence of competing influences on the eddy's trajectory, the $\beta$ plane continuously makes the eddy self-advect into the topography

\footnotetext{
${ }^{12}$ No drifters were drogued below this depth.
} 
and the interaction is always severe. Further, the simulated eddies spend large amounts of time at the shelf break (hundreds of days). The trajectory of large eddies in the ocean is certainly influenced by the presence of ambient flow features. Real eddies need not continually be at the shelf break, unlike the presented simulations. Our scalings are likely overestimates for this reason. It is necessary that these scalings be checked against longterm simulations that include additional variability similar to those of Stewart and Thompson (2015).

Second, there is no shelfbreak front in any of these simulations. Since the eddy has a much larger velocity signature than the shelfbreak jet associated with the front, we expect that predictions for the shelf-water outflow are unaffected by the presence of a front. Accordingly, laboratory experiments by Cenedese et al. (2013) indicate that for such "strong interactions," the shelf water is permanently exported and is sourced from inshore of the shelfbreak jet's velocity maximum. At the Mid-Atlantic Bight, existing observations and simulations do indicate that the front moves inshore where the eddy forces an inflow (e.g., Zhang and Gawarkiewicz 2015). The front appears not to prevent eddy water from crossing onto the shelf, so our results might be applicable at least when the eddy is at the shelf break. Once the eddy forcing has relaxed, the front should present a barrier to eddy water mixing in with shelf water. These assertions are very tentative and must be tested against high-resolution simulations involving a shelfbreak front, such as those reported by Zhang and Gawarkiewicz (2015).

Third, the onshore flux of eddy and slope waters has yet to be parameterized. Such a scaling is critical for assessing how important eddy-driven cross-shelf exchange is to closing the salt budget of Lentz (2010). Fourth, the apparent insensitivity of the supply jet's cross-shelf scale when bottom friction is varied significantly must be examined in more detail. Fifth, the simulations have ignored the effect of surface forcing as well as along-shelf topographic variations (e.g., canyons). Both might conceivably have an effect on flux magnitude and flow scales. Finally and perhaps most importantly, all predictions here must be tested against an extensive observational dataset. The eddy-shelf interaction problem still presents multiple intriguing challenges-ones that must be addressed with both high-fidelity numerical models and high-resolution observations.

Acknowledgments. This paper constitutes part of DAC's Ph.D. thesis. Both the thesis and this manuscript owe much to Steve Lentz's suggestions and many intriguing questions. Multiple stimulating discussions with Glenn Flierl and Amala Mahadevan are also gratefully acknowledged. We also thank two anonymous reviewers for kind and helpful feedback. We acknowledge highperformance computing support from Yellowstone (http:// n2t.net/ark:/85065/d7wd3xhc) provided by NCAR's Computational and Information Systems Laboratory, sponsored by the National Science Foundation. We also acknowledge high-performance computing support from Cheyenne (https://doi.org/10.5065/D6RX99HX) provided by NCAR's Computational and Information Systems Laboratory, sponsored by the National Science Foundation. The research presented here was funded by the U.S. National Science Foundation's Physical Oceanography program through Grants OCE-1059632 and OCE1433953. Funding support from the Academic Programs Office, Woods Hole Oceanographic Institution, is also gratefully acknowledged.

\section{REFERENCES}

Beardsley, R. C., D. C. Chapman, K. H. Brink, S. R. Ramp, and R. J. Schlitz, 1985: The Nantucket Shoals Flux Experiment (NSFE79). Part I: A basic description of the current and temperature variability. J. Phys. Oceanogr., 15, 713-748, https://doi.org/10.1175/ 1520-0485(1985)015<0713:TNSFEP $>2.0 . C O ; 2$.

Beron-Vera, F. J., Y. Wang, M. J. Olascoaga, G. J. Goni, and G. Haller, 2013: Objective detection of oceanic eddies and the Agulhas leakage. J. Phys. Oceanogr., 43, 1426-1438, https:// doi.org/10.1175/JPO-D-12-0171.10.

Brink, K. H., 1998: Deep sea forcing and exchange processes. The Global Coastal Ocean: Processes and Methods, K. H. Brink and A. R. Robinson, Eds., The Sea-Ideas and Observations on Progress in the Study of the Seas, Vol. 10, John Wiley and Sons, 151-167.

_, 2012: Buoyancy arrest and shelf-ocean exchange. J. Phys. Oceanogr., 42, 644-658, https://doi.org/10.1175/JPO-D-11-0143.1. , 2017: Surface cooling, winds, and eddies over the continental shelf. J. Phys. Oceanogr., 47, 879-894, https://doi.org/10.1175/ JPO-D-16-0196.1.

- R. Limeburner, and R. C. Beardsley, 2003: Properties of flow and pressure over Georges Bank as observed with nearsurface drifters. J. Geophys. Res., 108, 8001, https://doi.org/ 10.1029/2001JC001019.

Burger, A. P., 1958: Scale consideration of planetary motions of the atmosphere. Tellus, 10, 195-205, https://doi.org/10.1111/ j.2153-3490.1958.tb02005.x.

Cenedese, C., R. E. Todd, G. G. Gawarkiewicz, W. B. Owens, and A. Y. Shcherbina, 2013: Offshore transport of shelf waters through interaction of vortices with a shelfbreak current. J. Phys. Oceanogr., 43, 905-919, https://doi.org/10.1175/JPO-D-12-0150.1.

Chapman, D. C., 1985: Numerical treatment of cross-shelf open boundaries in a barotropic coastal ocean model. J. Phys. Oceanogr., 15, 1060-1075, https://doi.org/10.1175/1520-0485 (1985)015<1060:NTOCSO >2.0.CO;2.

_ , and K. H. Brink, 1987: Shelf and slope circulation induced by fluctuating offshore forcing. J. Geophys. Res., 92, 11741-11 759, https://doi.org/10.1029/JC092iC11p11741.

Chelton, D. B., M. G. Schlax, and R. M. Samelson, 2011: Global observations of nonlinear mesoscale eddies. Prog. Oceanogr., 91, 167-216, https://doi.org/10.1016/j.pocean.2011.01.002.

Cherian, D. A., 2016: When an eddy encounters shelf-slope topography. Ph.D. thesis, Massachusetts Institute of Technology, $135 \mathrm{pp}$. 
, and K. H. Brink, 2016: Offshore transport of shelf water by deep-ocean eddies. J. Phys. Oceanogr., 46, 3599-3621, https:// doi.org/10.1175/JPO-D-16-0085.1.

Csanady, G. T., 1978: The arrested topographic wave. J. Phys. Oceanogr., 8, 47-62, https://doi.org/10.1175/1520-0485(1978) $008<0047$ :TATW $>2.0 . \mathrm{CO} ; 2$.

Early, J. J., R. M. Samelson, and D. B. Chelton, 2011: The evolution and propagation of quasigeostrophic ocean eddies. J. Phys. Oceanogr., 41, 1535-1555, https://doi.org/10.1175/ 2011JPO4601.1.

Flierl, G. R., M. E. Stern, and J. A. Whitehead, 1983: The physical significance of modons: Laboratory experiments and general integral constraints. Dyn. Atmos. Oceans, 7, 233-263, https:// doi.org/10.1016/0377-0265(83)90007-6.

Holton, J. R., 1965: The influence of viscous boundary layers on transient motions in a stratified rotating fluid: Part I. J. Atmos. Sci., 22, 402-411, https://doi.org/10.1175/1520-0469(1965) 022<0402:TIOVBL>2.0.CO;2.

Joyce, T. M., J. K. Bishop, and O. B. Brown, 1992: Observations of offshore shelf-water transport induced by a warm-core ring. Deep Sea Res., 39 (Suppl.), S97-S113, https://doi.org/10.1016/ S0198-0149(11)80007-5.

Lee, C. M., and K. H. Brink, 2010: Observations of storm-induced mixing and Gulf Stream ring incursion over the southern flank of Georges Bank: Winter and summer 1997. J. Geophys. Res., 115, C08008, https://doi.org/10.1029/2009JC005706.

Lentz, S. J., 2010: The mean along-isobath heat and salt balances over the Middle Atlantic Bight continental shelf. J. Phys. Oceanogr., 40, 934-948, https://doi.org/10.1175/2009JPO4214.1.

Linder, C. A., and G. G. Gawarkiewicz, 1998: A climatology of the shelfbreak front in the Middle Atlantic Bight. J. Geophys. Res., 103, 18 405-18 423, https://doi.org/10.1029/98JC01438.

Marchesiello, P., J. C. McWilliams, and A. F. Shchepetkin, 2001: Open boundary conditions for long-term integration of regional oceanic models. Ocean Modell., 3, 1-20, https://doi.org/ 10.1016/S1463-5003(00)00013-5.

Mason, E., M. J. Molemaker, A. F. Shchepetkin, F. Colas, J. C. McWilliams, and P. Sangrà, 2010: Procedures for offline grid nesting in regional ocean models. Ocean Modell., 35, 1-15, https://doi.org/10.1016/j.ocemod.2010.05.007.

McWilliams, J. C., and G. R. Flierl, 1979: On the evolution of isolated, nonlinear vortices. J. Phys. Oceanogr., 9, 1155-1182, https:// doi.org/10.1175/1520-0485(1979)009<1155:OTEOIN >2.0.CO;2.

Mied, R. P., and G. J. Lindemann, 1979: The propagation and evolution of cyclonic Gulf Stream rings. J. Phys. Oceanogr., 9, 1183-1206, https://doi.org/10.1175/1520-0485(1979)009<1183: TPAEOC $>2.0 . \mathrm{CO} ; 2$.
Myers, R. A., and K. Drinkwater, 1989: The influence of Gulf Stream warm core rings on recruitment of fish in the northwest Atlantic. J. Mar. Res., 47, 635-656, https://doi.org/10.1357/ 002224089785076208.

Nof, D., 1983: On the migration of isolated eddies with application to Gulf Stream rings. J. Mar. Res., 41, 399-425, https://doi.org/ $10.1357 / 002224083788519687$.

Oey, L.-Y., and H. Zhang, 2004: The generation of subsurface cyclones and jets through eddy-slope interaction. Cont. Shelf Res., 24, 2109-2131, https://doi.org/10.1016/j.csr.2004.07.007.

Okkonen, S. R., T. J. Weingartner, S. Danielson, D. Musgrave, and G. Schmidt, 2003: Satellite and hydrographic observations of eddy-induced shelf-slope exchange in the northwestern Gulf of Alaska. J. Geophys. Res., 108, 3033, https://doi.org/10.1029/ 2002JC001342.

Pedlosky, J., 1987: Geophysical Fluid Dynamics. 2nd ed. Springer, $710 \mathrm{pp}$.

Ramp, S. R., R. C. Beardsley, and R. Legeckis, 1983: An observation of frontal wave development on a shelf-slope/warm core ring front near the shelf break south of New England. J. Phys. Oceanogr., 13, 907-912, https://doi.org/10.1175/ 1520-0485(1983)013<0907:AOOFWD>2.0.CO;2.

Shchepetkin, A. F., and J. C. McWilliams, 2003: A method for computing horizontal pressure-gradient force in an oceanic model with a nonaligned vertical coordinate. J. Geophys. Res., 108, 3090, https://doi.org/10.1029/2001JC001047.

, and — 2005: The regional oceanic modeling system (ROMS): A split-explicit, free-surface, topography-followingcoordinate oceanic model. Ocean Modell., 9, 347-404, https:// doi.org/10.1016/j.ocemod.2004.08.002.

Shi, C., and D. Nof, 1993: The splitting of eddies along boundaries. J. Mar. Res., 51, 771-795, https://doi.org/10.1357/0022240933223927.

Stewart, A. L., and A. F. Thompson, 2015: Eddy-mediated transport of warm Circumpolar Deep Water across the Antarctic shelf break. Geophys. Res. Lett., 42, 432-440, https://doi.org/ 10.1002/2014GL062281.

Tranter, D. J., D. J. Carpenter, and G. S. Leech, 1986: The coastal enrichment effect of the East Australian Current eddy field. Deep-Sea Res., 33A, 1705-1728, https://doi.org/10.1016/ 0198-0149(86)90075-0.

Zhang, W. G., and G. G. Gawarkiewicz, 2015: Dynamics of the direct intrusion of Gulf Stream ring water onto the MidAtlantic Bight shelf. Geophys. Res. Lett., 42, 7687-7695, https://doi.org/10.1002/2015GL065530.

$\longrightarrow,-$ D. J. McGillicuddy Jr., and J. L. Wilkin, 2011: Climatological mean circulation at the New England shelf break. J. Phys. Oceanogr., 41, 1874-1893, https://doi.org/10.1175/2011JPO4604.1. 